\title{
DEMOCRACIA EN CHILE, BÚSQUEDA SIN TÉRMINO*
}

\author{
Joaquín Fermandois \\ Pontificia Universidad Católica de Chile
}

\begin{abstract}
Resumen: ¿Qué tan democrático ha sido Chile a lo largo de su historia? ¿Qué tan real es el mito de su estabilidad política y apego institucional? ¿Hay suficientes argumentos para hablar de un excepcionalismo chileno? Este ensayo intenta responder algunas de estas preguntas y poner el caso de este país y su democracia en perspectiva histórica y comparada.

Palabras clave: democracia, historia institucional, Chile, Latinoamérica.
\end{abstract}

\section{DEMOCRACY IN CHILE, THE NEVER-ENDING QUEST}

ABstract: How democratic has Chile been over its history? How much substance is there to the myth of Chilean political stability and attachment to institutions? Are there sufficient grounds to speak of Chilean exceptionalism? This essay sets out to answer some of these questions and place the country and its democracy in a historical and comparative perspective.

Keywords: democracy, institutional history, Chile, Latin America.

\footnotetext{
Joaquín Fermandois Huerta. Profesor titular del Instituto de Historia de la Pontificia Universidad Católica de Chile e investigador del Centro de Estudios Públicos. Estudios de postgrado en Alemania Federal y España. Beca Guggenheim 1989. Email: jfermand@uc.cl.

*El autor expresa que esta investigación contó con la colaboración de Maximiliano Jara.
} 
omo lección aprendida, parecía ser verdad evidente que Chile había sido un país más ordenado que otros en el siglo XIX. En el XX, esa imagen pervivió hasta considerársela la democracia más estable de la región. Aunque siempre existió alguna visión que difería de este panorama, el asunto alcanzó la discusión política más intensa e inevitable desde 1973, y pesa todavía en la vida cultural y política del país; la discusión sobre este tema es parte del mismo proceso democrático. $^{1}$

La idea según la cual Chile ha sido un país más ordenado que otros de la región fundamentaba la noción de lo que se llama excepcionalismo chileno, concepto surgido de la historia norteamericana pero que ha sido aplicado a otros fenómenos que le son análogos. Implica alguna conciencia de superioridad y es, precisamente eso, de lo que muchos se han burlado o que provoca desdén, sobre todo a partir de 1973. Ha sido casi una especie de buen tono obligatorio en los medios destacar que todo esto habría sido un "mito", invención o construcción más o menos arbitraria para embellecer la autoconciencia nacional. Sería una especie de ideología o factor ideológico en la cultura chilena. La tesis que sostienen las líneas expuestas a continuación va más bien en la dirección de que Chile sí representó, más que otros países latinoamericanos, las tensiones - y también los quiebres - del proceso político democrático en el mundo moderno, aunque se concentra al interior de la sociedad chilena y su pugna por el poder político.

Aquí no puedo entrar a comparar los sistemas políticos latinoamericanos en la historia republicana. En razón de ello, concentraré esta reflexión sobre el tema en lo que parece más atinente: de si ese presunto

${ }^{1}$ En términos positivos, destaca Ricardo Krebs, Identidad chilena (Santiago: Centro de Estudios Bicentenario, 2008). También Sergio Villalobos, quien ve en la aristocracia el agente fundador de la institucionalidad chilena, Portales, una falsificación histórica (Santiago: Universitaria, 2016), 225-226. Clásico en este sentido es Francisco Antonio Encina, Historia de Chile: desde la prehistoria hasta 1891 (Santiago: Editorial Nascimento, 1940-1952). Una visión sólo crítica puede hallarse en Felipe Portales, Los mitos de la democracia chilena (Santiago: Catalonia, 2004); Gabriel Salazar, Violencia politica popular en las "Grandes Alamedas" (Santiago: Sur, 1990); un clásico que se refiere al temprano desarrollo de la democracia chilena, Samuel J. Valenzuela, Democratización vía reforma. Expansión del sufragio en Chile (Buenos Aires: Ides, 1985). También, véase una visión cualificada en Mario Góngora, Ensayo histórico sobre noción de Estado en Chile (Santiago: Universitaria, 2010). 
orden mostró algún grado de democracia real o más bien constituyó una máscara que escondía una sociedad tradicional, fundamentalmente oligárquica. Por ello, colocamos a la historia del Chile republicano, hasta el presente, en el marco de la pregunta de en qué grado el desarrollo chileno ha respondido a lo que se puede considerar un patrón democrático. De todas maneras, de acuerdo a lo que he planteado en otras partes, la definición de este problema en la historia del país no se puede delinear sin tener presente el desarrollo de la política moderna en su dimensión global, y se recordará en todo momento al lector que esto debe ser así.

\section{EL MODELO OCCIDENTAL}

¿Qué es la democracia? Las definiciones podrían atosigar los estantes de una biblioteca y aquí no tengo la intención de remedarlo con una larga enumeración, casi siempre sospechosa. Sólo pretendo ofrecer una categoría según las cual se apreciará el alcance y valor de la democracia chilena en la historia republicana. Este ensayo constituye una pincelada de un libro que interpretará, en lo básico, a todo el Chile republicano desde la perspectiva de si ha sido y es - o no- democrático.

Por democracia entiendo el tipo de sistema político que cristalizó, en el transcurso del siglo XVIII y primera mitad del XIX, como una de las experiencias políticas modernas - las otras son totalitarismo y autoritarismo- con sus manifestaciones en las dos naciones anglosajonas, en la Francia del XIX y en parte los países escandinavos. Sería un foco madre de la civilización moderna y, por eso, lo llamo "modelo occidental", con potencia cultural que puede alcanzar a toda la humanidad. Éste no surgió de la nada. Tuvo prefiguraciones indispensables en la polis griega y en la república romana. ${ }^{2}$ Sus raíces más inmediatas están en la historia europea con su pluralismo de poder, desde la sociedad medieval, haciéndose más complejo a lo largo de los siglos; y el pluralismo de soberanías políticas o Estados, en el espacio europeo. No ha sido sólo producto de una experiencia cultural específica, sino que anida, en último término, en una base antropológica relativa a la organización de los hombres en sociedad. Este mismo fundamento también coloca los

${ }^{2}$ Sobre los orígenes de la democracia, Óscar Godoy, La democracia en Aristóteles: los orígenes del régimen republicano (Santiago: Ediciones Universidad Católica de Chile, 2012). 
obstáculos que muestran lo arduo que es alcanzar un estadio que consideremos satisfactorio. Aunque sea la creación que más se aproxima al orden superior y posible del ser humano en el tiempo y en el espacio, como toda civilización, está provista también de grietas y abismos.

Se trata, en lo esencial, de un fenómeno político. Cuando se habla de "democracia social" o "democracia económica" se lo hace en forma un tanto metafórica. Sin embargo, por su apelación a una legitimidad que hunde sus raíces en el cuerpo social, le es indispensable ser acompañada, de manera más o menos próxima, por eso que se ha llamado el proceso de modernización socioeconómica, que le es contiguo pero que no define al fenómeno mismo. Cuando hablamos de "democracia consolidada" se quiere decir que, además de la estabilidad política en lo sustancial, ha sido contigua al desarrollo económico y social.

¿En qué consiste una democracia? La división de poderes le es esencial y no existe ninguna que merezca el nombre de tal cuando no se da esa articulación entre el poder ejecutivo, legislativo y judicial; la distinción entre Estado y sociedad civil, y la existencia de la opinión pública, entendida no sólo como libertad de comunicación privada y pública, individual o de grupos, sino que también como lo que posibilita que actores individuales y colectivos de la sociedad civil se planteen, en cuanto tales, de manera pública ante el Estado, entendido éste como los tres poderes en su conjunto. ${ }^{3}$ La práctica electoral competitiva que refleje esta noción es otro acompañante de la democracia. La suma cualitativa de estas realidades, codificadas, es lo que constituye un Estado de Derecho.

Y, ¿por qué una democracia como meta? ¿Para qué? Surgió como un proceso relativamente espontáneo, no del todo consciente, que más tarde se volvió paulatinamente un paradigma, aunque el vocablo admita tantas definiciones. Le es inherente una crítica a la democracia, a veces enmascarada como una democracia más profunda o esencial. El siglo $\mathrm{XX}$ fue rico en estos ejemplos y Chile no ha escapado a sus dilemas. La democracia de la modernidad está sometida al reto de la transformación material que creó un proceso que sólo de manera reduccionista denominamos Revolución Industrial, ya que sus cimientos preceden con mucho

${ }^{3}$ Del pozo sin fondo de estudios sobre el concepto de democracia aquí nombro mi metro regulador, uno más posible, uno grande, Giovanni Sartori, Teoría de la democracia (Madrid: Alianza Editorial, 1988 [1987]). En el mismo sentido, para América Latina, Paul W. Drake, Between Tyranny and Anarchy. A History of Democracy in Latin America, 1800-2006 (Stanford, California: Stanford University Press, 2009). 
a la segunda mitad del XVIII. Parte de ello, es la transformación de la dialéctica entre cambio y conservación en los dilemas modernos entre derecha e izquierda, si bien rara vez es una distinción tajante.

El orden social aparece ahora como campo de disposición. Por ello, despierta apetencias de brinco a una experiencia radicalmente distinta y evoca también instintos de conservación. La democracia es una marca que termina por derruir la legitimación trascendental o mágica del poder político, reemplazándola por otra de tipo relativo o racional. La experiencia totalitaria del siglo XX constituyó un proyecto más o menos inconsciente de rescatarla.

¿Es la democracia un sistema superior en lo civilizatorio? Sí, en la medida en que responde a un rasgo esencial de lo humano, la relativa autodeterminación de rango exacto desconocido, que le abre nuevos horizontes y también nuevos abismos. En la modernidad, por la contigüidad con los procesos materiales y la planetarización de la sociedad global, no parece posible su reemplazo por otros sistemas, sin regresión, para una humanidad que tenga a la cultura y civilización como modelo regulador.

\section{RAIIZ EN LA EUROPA DE RETAGUARDIA: ORIGEN DE CHILE}

Chile está vinculado por un cordón umbilical con la modernidad. Como país y sociedad, sus dos partos fundacionales se relacionan con estremecimientos globales. Primero, fue resultado de la expansión europea del 1500. Hijo de esa Europa que no creó la modernidad es que apareció la sociedad criolla y mestiza como proyecto inconsciente de nación, tal como en muchas partes de Hispanoamérica. Una fuente de su cimiento, las sociedades indígenas preexistentes, no respondía a una sociedad compleja sino que a una arcaica (o pre histórica). La síntesis factual que surgió durante la colonia dentro del margen del imperio español, tal como en otras partes de Hispanoamérica, tuvo menos rasgos de autogobierno que su contraparte de la América anglosajona. Diferencia cardinal. ${ }^{4}$

${ }^{4}$ Dos interpretaciones divergentes y complementarias son J. H. Elliot, Empires of the World. Britain and Spain in America 1492-1830 (New Haven, Londres: Yale University Press, 2006); Claudio Véliz, Los dos mundos del Nuevo Mundo. Cultura y economía angloamericana e hispanoamericana (Santiago: Tajamar Editores, 2009). 
Tras el momento fundacional del 1500, viene la creación republicana del 1800, parte de la creación de la política y, en general, de la eclosión de la modernidad. Este segundo parto fue también una pieza del primer eslabón del proceso de descolonización, comenzando por las trece colonias de la América anglosajona en 1776. La crisis de la Corona, a partir de 1808, fue otra cara de la transformación euroamericana y, finalmente, mundial. Llama la atención, en primer lugar, la rapidez con que la elite criolla - más extendida en su concepto de lo que comúnmente se diceadoptó el lenguaje de la política moderna de las tradiciones continentales de Francia e Inglaterra; también algo de Estados Unidos. Su práctica, claro, fue otra cosa. Con todo, mientras en América del Norte estaba la tradición del lenguaje político tanto clásico como aquel que iba siendo el liberalismo, en el sur sólo la "teoría del pacto" podría acercársele. ${ }^{5}$

\section{¿ORDEN, EXCEPCIONALISMO?}

Gran parte del debate respecto a si Chile ha sido democrático o no se ha concentrado en torno al desarrollo del siglo XIX. No sin discusión apasionada sobre el llamado sistema portaliano, cuya obra obtuvo valoración positiva y se transformó en visión dominante —en general— hasta 1973. Esta interpretación sostenía que Chile, junto a Brasil, había sido un país más ordenado que otros de América Latina y había constituido una excepción en el panorama de tragedia de Hispanoamérica, las "naciones de América del Sur", como con desdén hablaba Alexis de Tocqueville. ${ }^{6}$

${ }^{5}$ Ésta es la idea según la cual la legitimidad del monarca venía de la entrega que el pueblo le había efectuado de sus propias atribuciones y que una vez desaparecido el monarca debería retornar a ese mismo pueblo. En el caso de Chile, esta antigua noción peninsular está expresada en el Catecismo político cristiano de José Amor de la Patria. Un muy completo estudio de este decidor opúsculo en Walter Hanisch, El catecismo político cristiano. Las ideas y la época (Santiago: Andrés Bello, 1970). Como tanta manifestación cultural de la sociedad, no fue fenómeno aislado, sino que tenía raíz hispanoamericana y peninsular: Rafael Sagredo, De la colonia a la república. Los catecismos políticos cristianos, 1811-1827 (Madrid: MAPFRE, 2009).

${ }^{6}$ Sobre la idea de estabilidad de Chile, véase Ricardo Krebs, Identidad chilena; Véliz, Los dos mundos. Para una visión crítica, Brian Loveman, Chile: The Legacy of Hispanic Capitalism (Nueva York y Oxford, Oxford University Press, 2001 [1979]); entre muchos otros. Desde una visión crítica de la historia sudamericana, Alexis de Tocqueville, De la Democratie en Amérique (Paris: Gallimard, 1961): I, 166,169 y sobre todo 235 . 
La guerra por la Independencia fue menos sanguinaria que en otras partes; lo mismo que el descalabro político que siguió a la derrota realista, llamado muchas veces "anarquía", pero que también, quizás con justicia, se conoce como "aprendizaje". Eso como primer punto a considerar. ${ }^{7}$ Como segundo, el sistema que tuvo como principal actor a Diego Portales fue institucional y regulado, poco personalizado, con formas institucionales de alto grado de autoritarismo; en las formas, quizás, más avanzado, si comparamos con la mayoría de la Europa de la época. Con cambio regular de presidentes, persistió hasta comienzos de los 1860, en gran medida porque los gobiernos derrotaron rebeliones sucesivas hasta $1859 .{ }^{8}$ Siguió, hasta 1891 , una liberalización que es fundamental para definir el carácter democrático de una realidad política.

Hay tres rasgos de interés. El primero es que la violencia política conocida hoy como "represión" fue muy limitada, salvo en los campos de batalla, con alrededor de dos o tres mil muertos de los ejércitos o milicias comprometidos. ${ }^{9}$ Los derrotados se exiliaban por un tiempo y después se incorporaban, lo mismo que tras la Independencia. El segundo es que los presidentes en el fondo nominaban a su sucesor, como un antecedente al "tapado" mexicano, lo que no impidió una evolución en el campo político y electoral ni el surgimiento del pluralismo, otra condición básica de la democracia. Y el tercer rasgo es que en Chile el orden está intercalado por enfrentamientos violentos, al menos en lo político. Como el resto de Hispanoamérica - a partir de estos momentos "América Latina"—, seguía el mismo proceso que afectaría a España hasta mediados del XX.

\footnotetext{
${ }^{7}$ Una de los más reconocidos ensayos en hablar de anarquía y orden es Alberto Edwards, La fronda aristocrática: historia politica de Chile (Santiago: Universitaria, 1976), 56-60; Gabriel Salazar habla de ella como experiencia democrática verdadera "desde abajo", Construcción de Estado en Chile (1800-1837): democracia de los "pueblos", militarismo ciudadano, golpismo oligárquico (Santiago: Editorial Sudamericana, 2005). Por su parte, Julio Heise entiende ese período como uno de aprendizaje político, Años de formación y aprendizaje políticos: 1810-1830 (Santiago: Editorial Universitaria, 1978).

${ }^{8}$ Véase Joaquín Fernández Abara, Regionalismo, liberalismo y rebelión: Copiapó en la guerra civil de 1859 (Santiago: Editorial Finis Terrae, 2012).

${ }^{9}$ Véase Alejandro San Francisco, La guerra civil de 1891 (Santiago: Bicentenario, 2007-2008). Esta guerra provocó diez mil muertos, la cifra máxima en la historia republicana.
} 
Hasta 1861 (o 1891, o 1924), Chile fue una república conservadora, oligárquica, si se quiere, manejada por una "élite", palabra que, en nuestra época, lo explica todo y nada a la vez. ${ }^{10}$ Porque se trató también de una era de aprendizaje político y democrático. Se desarrollaron en particular dos de estas prácticas. Una es la de la regularidad de las instituciones, ejemplar en las sucesiones de presidentes. La segunda fue el hábito de los procesos electorales y el carácter competitivo, aunque no pasarían una prueba de blancura del siglo XX; tampoco, la estabilidad protegida por la capacidad del aparato gubernamental de influir en el resultado de las elecciones. ${ }^{11}$ Sobre todo, este proceso político hizo surgir, desde los albores de la Independencia, un elemento básico de la democracia, la clase política, esa con motivaciones políticas y sectores en potencia de una derecha y una izquierda.

Chile efectuó grandes progresos económicos en el XIX y, sin embargo, el tema dominante en el XX sería el subdesarrollo y la pobreza. ${ }^{12}$ ¿Qué sucedió? Si esa democracia no pasaría un examen en el siglo XX, su atraso, en relación con los países que denominamos desarrollados, estalló como tema de escándalo con la polémica del 1900. Chile no era diferente a otros países de la región y, algo evidente en el nuevo siglo, tenía mucho menos de democracia social que Argentina, el país más desarrollado. En este sentido, lo que sucedió en el XIX tuvo un alcance creativo limitado en comparación con el proceso democrático europeo occidental, pero tuvo relativa solidez en la región. Definiendo a la elite chilena del XIX como una "minoría creadora", algo distinto que una pura clase social, la constitución de una genuina clase política que adquirió autonomía puede ser un rasgo específico del siglo. Eso se explica porque, en este país, "la institucionalización precedió a la movilización".

${ }^{10}$ Una visión negativa puede hallarse en Julio César Jobet, Ensayo histórico del desarrollo económico-social de Chile (Santiago: LOM, 1985).

11 Antonio Annio (coordinador), Historia de las elecciones en Iberoamérica (Buenos Aires: Fondo de Cultura Económica, 1995). Un ejemplo concreto de la práctica en el sistema electoral, René Millar, La elección presidencial de 1920: tendencias y prácticas políticas en el Chile parlamentario (Santiago: Universitaria, 1982).

12 Alejandro San Francisco et al., Historia de Chile 1960-2010. Tomo I. Democracia, esperanzas y frustraciones. Chile a mediados del siglo XX (Santiago: Ediciones CEUSS, 2016), 149-157. 


\section{SURGIMIENTO DE LAS QUERELLAS IDEOLÓGICAS}

En toda sociedad humana parte de sus comunicaciones colectivas pueden definirse como ideológicas. Aquí, las acoto a un campo más restringido, propio de un fenómeno más evidente en el siglo XX, del cual Chile fue actor autoconsciente. Hacia el 1900, existen dos fenómenos que van a definir gran parte del debate del siglo, y, en cierto sentido, continuarán hasta el presente. Uno era la "cuestión social" ya mencionada. ${ }^{13}$ Lo segundo es que, desde el 1900, emergía una nueva izquierda, antisistema, entre socialista y anarquista, a veces de tipo socialdemócrata. Es una zona esencial del sistema de partidos del mundo moderno y quizás lo siga siendo, en tanto punto de referencia. Antisistema y no revolucionario, aunque con algo del espíritu de este último, inevitablemente, sería también canalizada por vías institucionales. ${ }^{14}$ No se produciría un "momento revolucionario" en el país: o no se sabían o podían aprovechar los momentos de crisis.

La izquierda moderna, sobre todo aquella que sería marxista, es antes que nada un fenómeno mental, un lenguaje, un discurso. La compañía probable de movimientos sociales, junto con extraer adherentes multiclasistas de la intelligentzia, era el mundo sindical y gremial. Y estuvo relacionada con hechos dramáticos, con decenas y hasta centenares de muertos, cuyo símbolo es la Escuela de Santa María de Iquique en 1907, manifestación de un tipo de represión, antes que se generalizaran nuevos métodos de control de multitudes. ${ }^{15}$ Surgía así un reto fundamental de la política moderna: el cómo integrar a una persuasión antisistema al corazón de una sociedad abierta, asumiendo sus reglas del juego. Así se podía cambiar el sistema de manera incremental y éste podía canalizar las inquietudes.

${ }^{13}$ Sergio Grez, De la "regeneración del pueblo" a la huelga general. Génesis y evolución histórica del movimiento popular en Chile (1810-1890) (Santiago: Dibam, 1997); Cristián Gazmuri, editor, El Chile del centenario, los ensayistas de la crisis (Santiago: Instituto de Historia de la Pontificia Universidad Católica de Chile, 2003).

14 Julio Pinto Vallejos y Verónica Valdivia, ¿Revolución proletaria o querida chusma? Socialismo y alessandrismo en la pugna por la politización pampina (1911-1932) (Santiago: LOM, 2001).

${ }^{15}$ Eduardo Devés, Los que van a morir te saludan. Historia de una masacre: Escuela Santa María de Iquique, 1907 (Santiago: LOM, 1997). 
Surgió un fenómeno adicional, un sismo del siglo XX, a partir de 1917: la Revolución Rusa y el comunismo, proceso en el que Chile sería un campo de seducción. ${ }^{16} \mathrm{Al}$ triunfar la revolución en una gran potencia, se hizo parte del corazón del sistema internacional hasta la década de 1980, lo que incluyó a otras versiones radicales antirrevolucionarias que en cierta manera eran también revolucionarias: su máxima expresión fue la Alemania nazi. Se trataba del fenómeno totalitario que despuntó, y en germen, con la Revolución Francesa y, ahora, en el siglo $\mathrm{XX}$, por momentos parecía presagiar el futuro de la humanidad. Todo esto tendría su correlato en la reacción de la política chilena, con todos sus matices. En la primera década del siglo ya estaban instalados tantos los discursos revolucionarios como los antirrevolucionarios típicos del nuevo siglo.

Sin embargo, este cuadro no estaría completo si no se añadiera que esta época de parlamentarismo u oligárquica — según repetidamente se la ha denominado - fue también de destacada regularidad institucional, en proceso análogo a lo sucedido en Argentina y quizás como parte de la "segunda ola de democratización", en torno a la Primera Guerra Mundial, que influyó en el Cono Sur en mayor medida que la de 1945. Tenía algo de un mundo "normal" y de la calma "burguesa" de la Monarquía de Julio en la historia francesa, a pesar de haber tenido tan mala reputación. ${ }^{17}$ Se la asocia también con el despertar de las clases medias, y, por ello, después se hablará del Chile de mediados de siglo como de "república mesocrática". En realidad, las clases medias no "aparecen" simplemente hacia el 1900. A grandes rasgos, toda sociedad compleja se puede entender articulada en tres sectores. Lo que es propio de la modernización socioeconómica es que la gran mayoría de ella adquiere el rostro de clase media, aunque en otros aspectos esto no sea completamente así. Lo que sucedió en Chile, entre el 1900 y la década de 1920, fue que mientras la clase media había sido un hecho de la causa y su clase política no surgía primariamente de allí, la legitimidad política está, desde estos momentos, ligada a traducir una exigencia de clase

${ }^{16}$ Joaquín Fermandois, La revolución inconclusa: la izquierda chilena y el gobierno de la Unidad Popular (Santiago: Centro de Estudios Públicos, 2013), 62-98.

${ }^{17}$ Samuel P. Huntington, La tercera ola. La democratización a finales del siglo XX (Barcelona: Paidós, 1994), 30-32. 
media. ${ }^{18}$ Por último, la modernización del Estado que vino a continuación, a 1927, fue casi en su totalidad debatida en la década que siguió; algo falló al momento de ponerla en práctica, vieja piedra en el zapato de los latinoamericanos.

\section{QUIEBRE, RENOVACIÓN, DICTADURA DE DESARROLLO, ABISMO}

Luego de 33 años, en un proceso que nace en septiembre de 1924 y continúa hasta 1932, se abrió otro período de quiebre de la democracia. ${ }^{19}$ No todo puede calificarse sin más de dictadura o no democracia, pues hubo una combinación como la que muchos países de Europa Oriental estaban experimentando, lo que sucedía a veces interminablemente en el resto de América Latina. Se dio una rebelión de oficiales jóvenes que derrocó al Presidente Alessandri; una junta militar conservadora; otra que representaba a los jóvenes con un caudillo naciente; una convocatoria con gran éxito al defenestrado Presidente, y una nueva Constitución con un impulso de reforma social y del Estado, esta última con participación norteamericana activamente propiciada por los "jóvenes turcos", expresión que se hizo célebre en la política y en la teoría política del siglo XX por la revolución militar en la Turquía de $1908 .^{20}$ De todo ello surgió un hombre fuerte que supervigilaba al nuevo Presidente electo por consenso a fines de 1925 bajo la ahora Constitución de 1925 , corazón del sistema hasta $1973 .{ }^{21}$ Después, sin embargo, provino una dictadura con exilio de una parte de la clase política de izquierda a derecha (se popularizaban estas palabras) y cooptación de otra parte de la clase política, un poco al estilo del régimen militar brasileño (1964-

${ }^{18}$ Azún Candina, Clase media, Estado y sacrificio: La Agrupación Nacional de Empleados Fiscales en Chile contemporáneo (1943-1983) (Santiago: LOM, 2013).

${ }^{19}$ Gonzalo Vial, Historia de Chile (1891-1973). Volumen III. Arturo Alessandri y los golpes militares (1920-1925) (Santiago: Santillana, 1987); Millar, La elección presidencial.

${ }^{20}$ Robert E. Ward y Dankwart A. Rustow, editores, Political Modernization in Japan and Turkey (Princeton: Princeton University Press, 1964), en especial referencias en capítulo de Peter F. Sugar, 161-164; en el de Kemal H. Karpat, 267-270, y en el de Dankwart A. Rustow, 373-377.

${ }^{21}$ Fernando Silva V., "Un contrapunto de medio siglo", en Historia de Chile, de Sergio Villalobos, Osvaldo Silva, Fernando Silva y Patricio Estellé (Santiago: Editorial Universitaria, 1977). 
1985). En términos internacionales, esto no era tema en el período de entreguerras.

Fue el sistema autoritario - como un régimen distinto al totalitario- el que emergió en los años de entreguerras. Como casos símbolos se pueden nombrar a la ya mencionada Turquía de Atatürk (1923), la China de Chiang Kai-shek (1925), la España de Franco (1939) y, en la segunda postguerra, el Egipto de Gamal Abdel Nasser (1952), inspirador del nacionalismo árabe. Fue una tendencia del siglo y quizás más allá de él, cuando la clase militar se convirtió en clase política, lo que llamó en especial la atención en América Latina, pero tuvo alcance global. ${ }^{22}$ Ya no el caudillo del XIX, sino que las instituciones armadas proporcionaban un cimiento político. Ésas fueron las juntas militares.

En este espacio no bastaba el orden: debía ser, además, un camino hacia una democracia fuerte, una especie de pedagogía que la restablecería una vez depurado el país de la corrupción, de la demagogia y de la desidia. Así, Carlos Ibáñez estableció la primera "dictadura de desarrollo" del siglo XX, bajo el amparo de la Constitución de 1925 como fachada, hasta su caída debido a los efectos de la Gran Depresión, en 1931. ${ }^{23}$ La siguió un período caótico, confuso, de una elección presidencial con un candidato de los partidos del sistema. Su derrocamiento, a instancias de oficiales que representaban un nacionalismo de izquierda y jóvenes que serían dirigentes socialistas — fundando la República Socialista de once días de duración-, tuvo significativas consecuencias. Siguieron golpes y contragolpes, rebelión de la marinería y rebelión comunista en Copiapó (los únicos hechos con derramamiento de sangre) y, al final, cansancio de los civiles con las intervenciones militares y cansancio de los uniformados con "la política". Fue un caos poco sanguinario; bajo Ibáñez casi no hubo muertos. Es probable que, en todo esto, operara la inercia institucional y la tendencia hacia la democracia dentro del modelo occidental.

22 Este problema, ambientado en la segunda mitad del siglo XX, lo trata Frederick M. Nunn, The Time of the Generals. Latin American Militarism in World Perspective (Lincoln: University of Nebraska Press, 1992).

23 Jorge Rojas Flores, La dictadura de Ibáñez y los sindicatos (1927-1931) (Santiago: Dibam, 1993); Joaquín Fermandois, Mundo y fin de mundo: Chile en la política mundial 1900-2005 (Santiago: Ediciones de la Universidad Católica, 2005), 102. 


\section{LA DEMOCRACIA COMO REFERENCIA: LAS DÉCADAS CLÁSICAS}

Si bien en la crisis de la democracia entre guerras Chile convivía con un elenco político análogo - aunque con distintas proporciones- a la Alemania de Weimar y la Francia de la Tercera República, con el segundo gobierno de Arturo Alessandri se inició una secuencia de 41 años de cambios regulares con el sistema político. Fue el punto de partida de una consolidación de la democracia que después de 1945 llamaría la atención, cuando el tema de ser o no democrático entra de lleno al debate interamericano. ${ }^{24}$ En sus formas - o contenido, un problema a pensarse - la sociedad chilena desarrolló una cultura democrática de consistencia, considerando el panorama regional y mundial, algo muchas veces soslayado por los análisis sobre el país. Desarrolló también un sentimiento de frustración inevitable en las democracias, pero exacerbado porque el proceso socioeconómico no mostraba una amplitud comparable al político. ${ }^{25}$ La práctica democrática, sin embargo, fue un hecho cierto, y a la vez, a partir de un momento, se hipotecó a sí misma.

En primer lugar, entre 1932 y 1973 el sistema de partidos y la regularidad electoral aseguraron la formación de una clase política habituada a normas y al acatamiento de los resultados, si bien muchas veces a regañadientes. Esta clase política —a veces también zaherida por la opinión pública y los medios, a veces despreciada - tenía más raíces sociales y configuraba un país político real, aunque convivía con un país antipolítico. El proceso electoral llegó a adquirir connotaciones de tibio carnaval y los procedimientos se depuraron. El cohecho - entiéndase, compra de votos - ya era marginal en los 1930 — eso sí, en elecciones ajustadas podía decidir el resultado- $-\mathrm{y}$ es probable que fuera un voto cautivo, pero ya no habrá huellas de él a fines de los 1950.

${ }^{24}$ En este sentido, son muy parecidas las palabras de Carlos Martínez Sotomayor - canciller de Jorge Alessandri-, de Eduardo Frei Montalva y de Salvador Allende. En Fermandois, Mundo y fin de mundo, 204; para Allende, véase Salvador Allende, "Discurso en la Asamblea General de Naciones Unidas, 4 de diciembre de 1972", en Salvador Allende y América Latina: 12 discursos y 2 conferencias de prensa, de Salvador Allende (México: Casa de Chile en México, 1978), 135.

${ }^{25}$ Dos críticos típicos de la época son Jorge Ahumada, En vez de la miseria (Santiago: Editorial Pacífico, 1958); Alberto Hurtado, ¿Es Chile un país católico? (Santiago: Ediciones Splendor, 1941). Un libro a debatirse, pero de título decidor, Aníbal Pinto Santa Cruz, Chile. Un caso de desarrollo frustrado (Santiago: Universitaria, 1958). 
Las campañas electorales eran ardorosas y el juego sucio no estaba ausente. El día de la elección era de calma chicha. El resultado mismo era de una rapidez extraordinaria. Para las ajustadísimas y polarizadas elecciones presidenciales de 1938, con un uno por ciento de diferencia entre los dos candidatos, el gobierno entregó el resultado a las 9:30 P.M., informando del triunfo del candidato opositor. Varias veces, eso sí, el perdedor fallaba a la caballerosidad democrática y no saludaba al vencedor o no lo reconocía moralmente; tan sólo lo aceptaba de hecho. El cuerpo electoral fue creciendo con el voto femenino (1949), un poco a la retaguardia en este caso del desarrollo en América y Europa, pero luego arrojó una alta participación. ${ }^{26}$ Nuevas medidas hasta 1962, con inscripción y voto obligatorio, conllevaron que en la década de 1960 sufragara un tercio de la población, entre el 70 y el 80 por ciento de los inscritos. ${ }^{27}$ Esto, junto con el activo sistema de partidos y la prensa libre - en la tradición del modelo occidental- y la importancia de la figura del Presidente, resume el corazón que alimentaba a esta democracia. Su símbolo máximo estaba en dos ritos. El primero: cualquier chileno podía ingresar a La Moneda y pasear por el corredor principal; el segundo (de más breve duración): el Presidente Jorge Alessandri (1958-1964) caminaba todos los días desde su departamento a La Moneda, situado a pocas manzanas, muchas veces completamente solo.

Dentro del sistema presidencial, los mandatarios nunca gozaron de una mayoría parlamentaria que los apoyara de forma segura. Incluso, tuvieron amargas disputas, las cuales, al final, lo esterilizaban casi todo con su propio partido o coalición, con la excepción parcial de Arturo Alessandri en los 1930. Se ha bautizado estos años como "Estado de compromiso", en el sentido de que había un pacto subyacente para que ninguna parte avasallara a la contraria, lo que se fue perdiendo en el

${ }^{26}$ Sobre el episodio de las elecciones de 1938 entre Gustavo Ross y Pedro Aguirre Cerda, véase Marcus Klein, "La elección presidencial de 1938", en Camino a la Moneda. Las elecciones presidenciales en la historia de Chile 1920-2000, de los editores Alejandro San Francisco y Ángel Soto (Santiago: Centro de Estudios Bicentenario / Instituto de Historia de la Pontificia Universidad Católica, 2005), 164-165; Fermandois, Abismo y cimiento: Gustavo Ross y las relaciones entre Chile y Estados Unidos (Santiago: Ediciones Universidad Católica, 1996), 27-64.

${ }^{27}$ Germán Urzúa Valenzuela, Historia política electoral de Chile: 1931-1973 (Santiago: Editorial Jurídica, 1986). 
curso de los $1960 .^{28}$ En cierta manera, a toda democracia le es propia una orientación hacia el compromiso expreso o mejor, tácito. Más que una fase hacia otro eslabón superior, fue un rozar una meta siempre elusiva, pero de la que se estaba más cerca o más lejos, y que es el vigor del modelo occidental en las costas del Pacífico sur. Además de los casos de América Latina, en el orden mundial estará la Grecia de la segunda postguerra, surgida de una guerra civil, cuya democracia fue derribada por un golpe militar antimarxista en 1967. Y la India, de Gandhi y Nehru, con conflictos innumerables, pero con un panorama general de estabilidad, con una breve excepción entre 1975 y 1977. Es el punto de fuga que nos hace aquilatar un fondo de verdad — si se puede llamar así- que había en la democracia chilena.

Lo nuevo — si bien tenía raíces en los 1930 - fue la instalación de la izquierda marxista en el paisaje político chileno, orientada hacia un sistema alternativo que admiraba a las grandes experiencias revolucionarias del siglo XX, el marxismo soviético, la Revolución Argelina, la Revolución Cubana, hasta que al final se agregó el régimen comunista de Alemania Oriental. Ser marxista, en este sentido, no era una manifestación esporádica, sino que en la militancia y en una subcultura política llegó a ser un modo de vida que exigía y al que se entrega un esfuerzo con abnegación. La persuasión socialdemócrata, o "reformismo", nunca tuvo muy buen nombre y luego sería repudiada por los socialistas, para los cuales, con contadas excepciones, Lenin llegaría a ser un compañero inseparable. Se vivía un espíritu revolucionario en un sistema institucional cuya regla sagrada — tabú, si se quiere - era que para ser integral debe acogerse a todas las posiciones e integrar a éstas convirtiéndolas en parte del sistema. ${ }^{29}$

La polaridad marxismo-antimarxismo definió la cultura política chilena entre los 1930 y los $1980 .^{30}$ No se trató de una polarización — sólo válida para los años de la Unidad Popular-, sino de polaridad, ya que por largas décadas las persuasiones intermedias, centro si se quiere, eran más numerosas e influyentes que los polos. Hacia

28 Tomás Moulian, "El régimen de gobierno 1933-1973. Algunos problemas institucionales", Documento de Trabajo Flacso 406, mayo 1989.

${ }^{29}$ Sobre el debate entre el alma rupturista y gradualista, véase Sergio Grez Toso, "La izquierda chilena y las elecciones: una perspectiva histórica (1882-2013), Cuadernos de Historia 40 (2014).

${ }^{30}$ Marcelo Casals Araya, La creación de la amenaza roja. Del surgimiento del anticomunismo a la "campaña del terror" en 1964 (Santiago: LOM, 2016). 
1970, la izquierda marxista se había identificado completamente con un proyecto revolucionario y sólo se dividía entre los partidarios de la acción directa y quienes insistían en la toma de poder institucional, con una mayoría esencial - la mayoría explotada - que debería, tarde o temprano, sumarse a sus filas. Si hubiera perdido las elecciones de 1970 — ganadas con el 1,4 por ciento de los votos-, una parte de ella se hubiera deslizado a la insurrección de un modo u otro; diez años después la evolución de la política mundial hubiera hecho surgir la fuerza reformista. El marxismo sabía convivir con el sistema estando en la oposición, participando en las instituciones y no encabezando el gobierno; si sucedía lo último, estaba condenada a encaminarse al modelo revolucionario.

La historia ideológica de Chile no se relaciona sólo con la Guerra Fría - en la cual fue prominente el papel de las llamadas superpotencias, aunque tampoco fue lo único-, sino que también deviene de una larga trayectoria en la que destaca su enraizamiento en las querellas ideológicas del siglo XX y en los dilemas entre democracia, autoritarismo y totalitarismo. Es de esta manera que Chile se integró, como un actor activo desde un primer momento, a la Guerra Fría, entendida ésta no sólo como juego de superpotencias, sino que también de fuerzas que pugnaban entre modelos alternativos enraizados en la modernidad. ${ }^{31}$

La subordinación de los militares a las instituciones políticas es lo que distinguía a Chile de otros países latinoamericanos. De hecho, había sido una base de esta democracia de referencia que era el Chile desde 1932, y hacia 1960 parecía que estaba la pleamar del retiro de los uniformados del interés público, hasta crearse un foso entre la vida militar y la civil. Por cierto, la noción de seguridad nacional —algo exagerada después por los estudiosos-o la defensa de las fronteras parecían, en la mayoría de los uniformados, implicar una posición antimarxista frente a una revolución de este tipo. ${ }^{32}$ En contrapartida, sobre todo en el

${ }^{31}$ Fermandois, Mundo y fin de mundo; Fermandois, La revolución inconclusa; Tanya Harmer Harmer, El gobierno de Allende y la guerra fría interamericana (Santiago: Ediciones Diego Portales, 2013); Fernando Purcell y Alfredo Riquelme, coordinadores, Ampliando miradas: Chile y su historia en el tiempo global (Santiago: RIL, 2009).

32 Frederick M. Nunn, The military in Chilean History: Essays on Civil-military, 1810-1973 (Albuquerque: Albuquerque University of New Mexico Press, 1976). 
personal subalterno, se habían desarrollado, por mucho tiempo, células que respondían al mundo de la izquierda marxista. El tema de la guerra de insurgencia se añadió al de la preparación para defender las fronteras del país; también había algún tipo de identificación con algunos rasgos centrales de la economía política nacional que se podría denominar desarrollismo. ${ }^{33}$

La sensación de crisis en los años 1960 y los reclamos gremiales de los uniformados precipitaron una primera fase de repolitización a fines de la década. La polaridad política que se convertía en polarización dejaba indicios de penetración en el cuerpo de las instituciones armadas. El hecho de que Chile estuviera rodeado de regímenes militares, y que Brasil ejerciera alguna hegemonía ideológica, proyectaba una influencia contradictoria: la de ser un país de excepción, la del peligro para las fronteras y la de la legitimidad relativa de la potencial intervención militar en política. El que oficiales superiores hubieran complotado con cierta anuencia política y apoyo norteamericano en septiembre y octubre de 1970 - lo que incluyó el asesinato no premeditado del general Schneider, comandante en jefe del ejército - se debía a la conciencia antirrevolucionaria que también definía al ambiente político.

\section{HACIA LA GUERRA CIVIL POLÍTICA}

El objetivo de la Unidad Popular era efectuar la "transición al socialismo" en los seis años del período presidencial; cuando Allende entregase el mando todavía no habría un auténtico socialismo, el de los países marxistas; no hay otra manera de decirlo. ${ }^{34}$ Los opositores lo sabían, intuían, elucidaban. Las bases del sistema habrían cambiado radicalmente y el nuevo estado de cosas estaría apoyado por esa mayoría esencial que es el pueblo o sus representantes. Se ha

33 John R. Bawden, The Pinochet Generation. The Chilean Military in the Twentieth Century (Tuscaloosa: University of Alabama Press, 2016).

${ }^{34}$ Fermandois, La revolución inconclusa; Adolfo Ibáñez Santa María, Historia de Chile: 1860-1973. Tomo II (Santiago: Editorial Bicentenario, 2014); Arturo Valenzuela, El quiebre de la democracia en Chile (Santiago: Flacso, 1989); Luis Corvalán Márquez, Del anticapitalismo al neoliberalismo en Chile. Izquierda, centro y derecha en la lucha entre los proyectos globales, 1950-2000 (Santiago: Editorial Sudamericana, 2001). 
destacado que el procedimiento fue rigurosamente constitucional. En efecto, lo fue en sus formas, pero con rechazo íntimo al espíritu tanto de la Constitución como del modelo occidental. En el discurso de la izquierda marxista antes del triunfo electoral de 1970, las referencias a la Constitución eran negativas; sólo cuando pasa a ser parte de la legitimidad de Allende como Presidente, será canónico lo del carácter constitucional del proyecto. No podía ser de otra manera; había poco espacio para la violencia revolucionaria y la izquierda no estaba preparada para ella ni tenía mucha experiencia, aunque un sector de la misma se sumaba incluso en la preparación desde mediados de los 1960. En caso de consolidación del socialismo - tal como era entendido por la Unidad Popular - quizás hubiera significado un "socialismo real" más liberal, aunque no haya ninguna experiencia al respecto en todo el siglo XX.

La "experiencia chilena" tuvo dos rasgos distintivos. Uno: que Allende, a pesar de la proyección internacional con que se lo invistió, no era el líder indiscutido de un proyecto al modo como Lenin lo fue en Rusia, Mao en China, Castro en Cuba o Ho Chi-Minh en Vietnam, y esto lo privó de capacidad estratégica (aunque era un gran táctico). El otro: que en esas reglas del juego la Unidad Popular jamás alcanzó una mayoría política en elecciones, salvo en una municipal. Es cierto que el factor institucional fue acompañado de una movilización, casi siempre semilegal, con ocupación de la calle, hasta que la oposición, con unidad precaria pero real en momentos decisivos, respondió con una contramovilización; en realidad, ésta más bien surgió de una sociedad civil que estallaba. Desde octubre de 1972 hasta el día del golpe el país vivió en una suerte de "guerra civil política", en la cual la mayoría de la población se divide en dos sectores en los que se escindió el cuerpo político, a la vez que cada segmento cree que no puede vivir con el otro. Hubo casi cien muertos por violencia política en los tres años del gobierno de Allende, máxima cota en la democracia clásica.

La Unidad Popular tenía una noción de democracia como desplazamiento, movimiento hacia una meta: la sociedad socialista. La misma Constitución — para volver a ella - sólo era válida como vía de salida a una nueva realidad, si es que podía construirse algo distinto y casi opuesto a lo que ya existía. Esto se aprecia en la Declaración de la Cámara del 22 de agosto de 1973 — una apenas velada convocatoria a las 
fuerzas armadas - y en la respuesta de Allende en la que decía que se referían dos constituciones distintas. Así era en efecto. ${ }^{35}$

Los militares estaban mucho más sometidos a dudas constantes acerca de su papel en épocas de crisis que lo que se supone. El escenario de la Guerra Fría estaba inscrito en la cultura política; no era sólo refracción de un esquema internacional bipolar; éste, como la realidad global, se filtraba por la experiencia histórica de Chile. Mientras el sistema sorteaba las crisis, los uniformados mantuvieron el papel institucional; cuando la guerra civil y política se expandió a gran parte de la sociedad fue entonces cuando penetró en el mundo militar. Ha habido una clase militar que fundó regímenes de izquierda nacionalista aunque con rapidez originan un autoritarismo rígido y en cierta manera conservador, como el del nacionalismo árabe. Nunca, con la sola excepción de Etiopía en 1974, un ejército tradicional ha encabezado una revolución radical de tipo marxista.

\section{EL RÉGIMEN DE PINOCHET}

Surgido de una abismal crisis del Estado y la sociedad, el régimen de Pinochet, semiinstitucional y semipersonalista, no fue más que la profundización y permanencia de la misma crisis en la década de 1970. ${ }^{36}$ Nació de una emoción previa más fuerte que la de los oficiales de 1924. Nació también con una voluntad de instaurar un período de renovación, en el cual el empleo de la fuerza le era fundamental y que no debía - ni podía, por lo demás - consistir en una simple deposición del Presidente.

Como todo estado de excepción que parece eternizarse, esta dictadura, en suma, transitó desde una legitimación en la primerísima hora

${ }^{35}$ Luis Corvalán Márquez, Los partidos políticos y el golpe del 11 de septiembre. Contribución al estudio del contexto histórico (Santiago: Universidad Bolivariana, 2000). Sobre la idea de democracia en la Unidad Popular y su carácter de moverse hacia algo distinto, véase Diego Hurtado, Las palabras no se las lleva el viento: lenguajes políticos y democracia durante el gobierno de la Unidad Popular (19701973), tesis de magíster en historia, Pontificia Universidad Católica de Chile, 2015.

${ }^{36}$ Sobre el régimen de Pinochet se han escrito varios trabajos, entre ellos aparecen Carlos Huneeus, El régimen de Pinochet (Santiago: Debate, 2016); Robert Barros, La junta militar: Pinochet y la Constitución de 1980 (Santiago: Editorial Sudamericana, 2005); Gonzalo Rojas, Chile escoge la libertad. La presidencia de Augusto Pinochet Ugarte 11. IX. 1973 - 11. III. 1981 (Santiago: Zig-Zag, 1998). 
de violación de la Constitución por parte de la Unidad Popular, hasta otra, de preparación del país para una democracia ulterior, más segura, ajena a tentaciones totalitarias, aunque, en términos puramente políticos se asemejó, al comienzo, a un régimen de "Estado total". Esta democracia ulterior se transformó en la razón política de una primera fase del régimen. Más que el golpe mismo, es la voluntad de cambio radical de régimen, prescindiendo de manera absoluta de la clase política formal - pese a que sectores mayoritarios de la misma habían dado su apoyo en diverso grado al golpe mismo-, lo que hizo de este momento el período más antidemocrático de la historia de Chile republicano (que, por cierto, no surgió de una pura veleidad, sino de una crisis de la democracia). Sin embargo, la democracia que lo siguió tuvo sus raíces en la experiencia del régimen y en sus opositores, como en la evolución mundial, reproduciendo el proceso de la modernidad como tránsito desde los sistemas autoritarios premodernos a la democracia.

Primero, fue el período más antidemocrático no sólo por el golpe mismo y la ausencia por un tiempo de casi todo pluralismo, sino que también por la violencia desatada después de la toma del poder, una vez asegurado el control del país. De alrededor de tres mil muertos del período entre 1973 y 1990, casi el 60 por ciento corresponde al lapso entre septiembre y diciembre de 1973, y sólo una cantidad mínima de ellos se originaron en circunstancias de lucha armada. ${ }^{37}$ Existía un aparato militar de la Unidad Popular, menor de lo que temían y exageraron sus adversarios y partidarios, aunque real. Éste fue desactivado porque falló tanto la dirección como un presupuesto: la división de las fuerzas armadas. La muerte de Allende le robó el principal incentivo de lucha. El resto de los muertos puede dividirse en varias categorías. En una estuvieron los fusilados en diversas provincias como forma de comprometer a oficiales del ejército y de amedrentar a los restos de la Unidad Popular, de lo cual la Caravana de la Muerte fue el episodio principal. En otra, estuvieron las muertes llevadas a cabo por el Comando Conjunto y más que nada por la Dina entre 1974 y fines de 1976, con la finalidad de

${ }^{37}$ Corporación Nacional de Reparación y Reconciliación, Informe sobre calificación de víctimas de violaciones de derechos humanos y de la violencia política (Santiago: Corporación Nacional de Reparación y Reconciliación, 1996), 539. De un total de 3.196 víctimas, 1.824 corresponden a los meses entre septiembre y diciembre de 1973. Según un recuento, hubo 47 víctimas uniformadas de la violencia en los años del régimen. La Tercera, 11 de septiembre de 2016. 
destruir las organizaciones clandestinas, en general no armadas, de los partidos de izquierda, formadas antes del golpe. Sólo una mínima parte de ellas estaba preparada o tenía un proyecto y trayectoria de lucha armada. Por ello, se llama a esto terrorismo de Estado. Aquí se originó la mayoría de los detenidos-desaparecidos, que según las evidencias eran torturados hasta morir.

Hay una etapa de remanso entre 1977 y 1980, excepto por un intento de crear guerra de guerrillas en Neltume por parte del MIR, cuyos combatientes fueron exterminados. Después, vino la violencia insurgente y la represión esporádica. Más adelante, de una forma muy organizada a partir del bloque soviético y de Cuba, el Frente Patriótico Manuel Rodríguez (FPMR) por tres años creó lo que se llamó guerrilla urbana, muy eficaz, aunque de alcance limitado y, al final, derrotada en lo militar y en lo político. ${ }^{38}$ La lucha de contrainsurgencia encabezada por una organización más racional, la CNI, terminó por recurrir, de manera más ocasional que la Dina, a formas horribles de represión, que crearon alarma pública precisamente porque había más libertad de expresión. No fue sistemático y había una real amenaza militar. El FPMR surgía de una fe en una orientación de raíz totalitaria, si bien en muchos casos nacida de una emoción comprensible. Finalmente, estuvieron las víctimas de las movilizaciones políticas en torno a las "protestas", a veces de mucha violencia, seguidas de represión excesiva en su contención entre 1983 y 1986. Fue algo parecido a la alta cantidad de víctimas de ambos sectores que existió durante los años de la Unidad Popular.

Para el límite espacial de este ensayo me he detenido en este punto, ya que es lo que pesa gravosamente, no sólo sobre los actores del régimen militar - en especial Augusto Pinochet, Manuel Contreras y sus numerosos colaboradores y partidarios-, sino que también sobre el Chile que devino, que en parte se originó en la experiencia directa en estos años. Esto es una referencia abierta o latente del debate de nuestros días. No cabe duda de que la responsabilidad central recae en los jefes. ¿Es posible y es siquiera sano destruir todo vestigio de pecado original? Lo "inevitable" en el número de víctimas aparece muy avaro en relación con la totalidad de las víctimas, los más numerosos casos de detenidos torturados y el exilio forzoso al menos para más de 30 mil

${ }^{38}$ Sobre la izquierda en la clandestinidad, véase Rolando Álvarez, Desde las sombras. Una historia de la clandestinidad comunista (Santiago: LOM, 2003). 
personas, más sus familias. La crisis previa puede ser homologada a las grandes crisis ideológicas de la modernidad, pero estos hechos de represión no tenían antecedentes en la historia de Chile.

El otro rasgo del régimen militar fue su carácter semiinstitucional, régimen de las fuerzas armadas en un grado que no tuvo el gobierno de Ibáñez en los 1920; y fue un régimen semipersonalista en torno a quien llegó a ser su líder, el general Pinochet, el que se invistió de un poder - y boato- al que no podían aspirar ni siquiera los gobernadores de los siglos coloniales. Incluso, el itinerario constitucional y la transición a la democracia planeada a partir de 1977 estaban muy manufacturadas para sus expectativas personales. Para mayor paradoja, fue el actor que, al final, le entregó más dirección estratégica, incluyendo a la parte creativa de una nueva realidad que ayudó a configurar el Chile actual.

Fue un régimen autoritario, no totalitario. Asumió la totalidad del poder público y pretendió dirigir y copar los debates públicos, pero había relativa autonomía en otros ámbitos. Por instantes, ha habido en el siglo XX regímenes autoritarios mucho más sanguinarios que algunos totalitarios. Chile, en la época de la Dina, era más feroz, en lo político, que la Hungría o Polonia contemporáneas, pese a que estos todavía tenían vigente gran parte o la totalidad de su armazón totalitaria.

Con todo, nunca dejó de haber algún grado de libertad política en Chile, al comienzo precaria y después más vital; ya sea en la existencia de la Iglesia Católica, todo un caso de actor político que se enfrentó al régimen no sin desgarro en sus filas y en sus fieles; en algunas $\mathrm{ONG}$, entre las que sobresalían la Flacso y la Cepal (esta última no hacía ningún asomo en Cuba, pero sí dejaba muy en claro su posición ante el caso chileno); radios y revistas autocensuradas de oposición. ${ }^{39}$ Sobre

39 Véase Rolando Franco, La Flacso clásica (1957-1973). Vicisitudes de las ciencias sociales latinoamericanas (Santiago: Flacso-Chile, Catalonia, 2007); Patricio Silva, "Technocrats and Politics in Chile from the Chicago Boys to the Cieplan monks", Journal of Latin American Studies 23, n. ${ }^{\circ} 2$ (1991). Sobre la acción de los centros académicos durante la década de 1980, véase Jeffrey Puryear, Thinking Politics. Intellectuals and Democracy in Chile, 1973-1988 (Baltimore y Londres: The Johns Hopkins University Press, 1994); Manuel Antonio Garretón, "Social Science and Society in Chile: Institutionalization, Breakdown and Rebirth", Social Science Information 44, n. ${ }^{\circ} 1$ y 3 (2005). Sobre la radio, véase Carla Rivera Aravena, "La verdad está en los hechos: una tensión entre objetividad y oposición. Radio Cooperativa en dictadura", Historia 41, n. $^{\circ} 1$ (2008). 
todo, no fue un régimen estático y esto es clave para comprender la transición a la democracia.

Nunca ha habido régimen militar de alguna duración en el que no haya ocupado un lugar destacado, al menos, una parte de la clase política, comprendida en un sentido amplio. En un primer momento, su apoyo fue la oposición a la Unidad Popular, pero el antimarxismo se disolvió en cuestión de semanas, aunque pervivió en cierta mayoría un vago sentimiento de rechazo a ese pasado; la participación de la Democracia Cristiana fue parcial y finalizó antes de los dos años. Quedó, básicamente, la antigua derecha - aunque no aceptada como tal por el régimen - y sectores anexos a ella y otros, como el gremialismo de Jaime Guzmán, que representaba a una derecha emergente. Los nacionalistas más puros tuvieron un papel subordinado, de poco peso en el desarrollo del sistema. Surgió un tipo de empresario y de economista como intelligentzia, que repitió un discurso tecnocrático que no veía mayor problema en la situación, pero que, con su propia palabra, debilitaba lo que podía haber de creencias fundamentales del régimen, ya que el puro lenguaje económico jamás ha sido suficiente como justificación política en el siglo XX. Aquí la libertad era la libertad económica. Gran parte de la legitimidad del régimen se jugó en este plano, y por ello puede ser denominada la segunda dictadura de desarrollo del siglo.

Este apoyo de la gran mayoría de la antigua derecha, ¿demostró descreimiento en la democracia o francamente una conducta antidemocrática? Se respondía con un supuesto, también tácito, según el cual la libertad económica era más apetecible que la libertad política, una especie de materialismo histórico liberal. La economía fundaría a la política. En un primer momento, hubo un descanso total en el régimen, sin pensar ni querer pensar en su cambio; no se tomó el peso tanto a la gravedad de los excesos - hasta que el caso Letelier amenazó con un descalabro mayor-, ni a pesar de la experiencia latinoamericana de inestabilidad inherente de cualquier autoritarismo. Luego, hay tres momentos cuando actores de derecha influyen en apuntar hacia un grado de retorno a la democracia. El primero fue hacia 1977, con la disolución de la Dina y el enfoque hacia una democracia supervigilada, un poco como el modelo coetáneo en Brasil. El segundo fue en torno a la grave crisis que se delineaba en 1982 y 1983, cuando se aceptó, en la práctica, la acción pública de muchos partidos opositores y se ampliaba el rango 
de tolerancia. ${ }^{40} \mathrm{Y}$ el tercero fue a raíz de la derrota de Pinochet en el plebiscito de 1988 y se anotó la fragilidad de un orden que no fuera asumido también por la oposición. Así se llegó a un amplio acuerdo con ésta para reformar la Constitución y ampliar el espíritu democrático de la misma en medio de un ambiente de pacificación del país. Al mismo tiempo se fundaba así, en la práctica política, lo que sería la "democracia de los acuerdos".

En paralelo vino una gran transformación en la cultura política de izquierda, que incubó principalmente el exilio europeo. ${ }^{41}$ Mientras en los 1950 y 1960 el mundo cultural europeo irradiaba una cultura política radical hacia el llamado Tercer Mundo, ahora el exilio se encontró con un fenómeno inverso, con una crítica al marxismo más allá de la anterior crítica al estalinismo. Quizás ello permitió a la izquierda chilena abrirse a la socialdemocracia, la izquierda posible dentro del modelo occidental, antes vilipendiada como "reformista", una grave descalificación en el mundo progresista chileno de los 1960 y de la Unidad Popular. También hubo desilusión de una parte de esa izquierda ante la experiencia directa con los sistemas marxistas. Este hallazgo es uno de los fundamentos más sólidos de la refundación de la democracia chilena. Hay otros.

Uno de ellos consiste en el aparato institucional y en la estrategia de economía política del régimen militar, racionalizado en el lenguaje tecnocrático. ${ }^{42}$ ¿Ayudó a la democracia? Fortaleció a la sociedad civil económica y fue parte de una pluralidad de poderes, si bien la con-

40 Pablo Rubio Apiolaza, Los civiles de Pinochet. La derecha en el régimen militar chileno, 1983-1990 (Santiago: Dibam, 2014); Tomás Moulian y Isabel Torres Dujisin, "La reorganización de los partidos de la derecha entre 1983-1988", en Documentos de Trabajo Flacso 388, noviembre 1988.

${ }^{41}$ Eugenio Ortega Frei, Historia de una alianza politica: el Partido Socialista y el Partido Demócrata Cristiano. Tesis para optar al grado de licenciatura en historia, Pontificia Universidad Católica de Chile, 1992); Mariana Perry, La dimensión internacional del pensamiento político chileno. Aprendizaje y transferencia en el exilio, tesis doctoral de la Universidad de Leiden, 2016; Puryear, Thinking Politics. Mireya Dávila Avendaño, Historia de las ideas de la renovación socialista 19741989, tesis de licenciatura en historia, Pontificia Universidad Católica de Chile, 1994.

42 Mario Góngora incluye en esta perspectiva como parte de las "planificaciones globales" no sólo al régimen militar, sino que también a los gobiernos de Eduardo Frei y Salvador Allende, en Ensayo histórico sobre noción de Estado en Chile, 280-305. 
vivencia entre régimen autoritario y economía de mercado, amén de muy abierta al mundo, ha sido un hecho bastante repetido. Ayudó así de forma oblicua a fortalecer una atmósfera diversa pero no existe una causalidad directa. Quizás en Chile el empresariado, a través de sus organizaciones, había tenido un papel más político que en otras partes no era puro lobby - y en un momento, sobre todo en 1988, entendió la necesidad de asumir una apertura decidida a la democracia (la derecha tradicional lo entendía desde 1983). ${ }^{43}$

Hubo evolución del régimen en etapas más marcadas que en la España franquista o la Polonia de Jaruzelski. En efecto, desde un primer momento franquista, por llamarlo así — una inspiración fundante hasta 1977—, éste se vio inviable por varias razones que confluían. La Dina se escapó de las manos con el caso Letelier; la llegada de la administración Carter había terminado por colocar a Estados Unidos en una posición hostil al gobierno chileno, aunque al final no tomó medidas demasiado duras; temía un desenlace revolucionario. La transición, en España, demostró lo difícil que era construir un régimen autoritario que sobreviviera en el tiempo, sobre todo en Europa y en América Latina. Los sectores —o la nueva descripción quizás más acertada de "sensibilidades" - de derecha habían sido formados por más de siglo y medio republicano; le conferían algunos rasgos autoritarios a la democracia, pero no se sentían familiares con una ordenación autoritaria de tipo corporativista, y utópica, por lo demás. En cada instancia, como las nombradas - y en el proceso en que estaban comprehendidas-, fue imponiéndose esta consideración de la mayoría de los asesores —no quizás los más directos— del régimen de Pinochet, y que podrían llamarse de derecha. ¿Prueba un talente democrático o mera táctica? Quizás ante el miedo de un momento revolucionario —rara vez de desenlace democrático si éste logra vencer- existe la

43 Joaquín Fermandois, "Modernización, desarrollo, dictadura: el papel de Sergio de Castro", Estudios Públicos 108 (2007): 281-313; Rodrigo Vergara, "Sergio de Castro, el arquitecto del modelo chileno (comentario al libro de Arancibia y Balart)", Estudios Públicos 110 (2008): 1-11; Arturo Fontaine Aldunate, Los economistas y el presidente Pinochet (Santiago: Zig-Zag, 1988); Juan Gabriel Valdés, La Escuela de Chicago. Operación Chile (Buenos Aires: Grupo Zeta, 1989); Manuel Gárate Chateau, La revolución capitalista de Chile: 1973-2003 (Santiago: Ediciones Universidad Alberto Hurtado, 2013). 
preferencia a largo plazo por el autoritarismo. También operaba el temor a que del golpe de 1973, como la extrema violencia que lo siguió, cultivaran un afán de venganza inextinguible en la persuasión revolucionaria, que ahora no tendría miramientos dado que combatía a una dictadura ${ }^{44}$ En la mentalidad del régimen la cultura del antimarxismo siguió ocupando un lugar.

Hay una etapa que culmina en 1977 con la disolución de la Dina y el naufragio del proyecto autoritario (se llamó "democracia autoritaria") puro si es que existió como tal, y la decisión de crear una democracia "protegida" y, añadimos, postergada hasta la década de 1990. La Constitución de 1980 en cierta medida corresponde a esta idea aunque en un ambiente político algo más abierto. El plebiscito de 1980, y todo lo que lo rodeó, no sería aceptable en ninguna versión del modelo occidental, aunque la oposición - liderada en lo visible por Eduardo Frei- pudo asomar su cabeza en público. El régimen sabía que corría contra el tiempo y que, además, era importante que los oficiales hubiesen jurado a una constitución; esa tradición tenía alguna fuerza.

La crisis de los años de las protestas — resultado más del derrumbe económico de 1982 antes que de la limitada apertura política - abrió otra compuerta. Esta crisis y las protestas subsecuentes llevaron a que en 1983 el gobierno asumiera que debía aceptar a la oposición democrática e incluso llevar a cabo una negociación inconducente con ella. Parte de este proceso fue el Acuerdo Nacional prohijado por el cardenal Juan Francisco Fresno, carente de resultado práctico. Fue, sin embargo, la primera vez en que fuerzas de derecha a izquierda —o la mayoría de éstas - convinieron en un marco relativamente común en lo político y económico, con adhesión explícita al modelo occidental. El régimen sobrevivió a la crisis pese a las extremas turbulencias internas y la presión externa. No obstante, pagó un precio. Ese precio fue que la apertura, valga la redundancia, abrió todavía más una puerta a una opinión pública que actuaba dentro del régimen o de sus propios simpatizantes. En 1985, una institución nombrada por el gobierno, el Tribunal Constitucional, tomó una decisión que obligó a que el futuro plebiscito se reali-

${ }^{44}$ Arturo Fontaine Talavera, "Sobre el pecado original de la transformación capitalista chilena", en El desafio neoliberal: el fin del tercermundismo en América Latina, del compilador Barry Levine (Barcelona: Norma, 1992), 93-119. 
zara de acuerdo a las reglas del juego de un sistema democrático. ${ }^{45}$ No podría haber otro plebiscito relativamente manipulado.

El triunfo del No en el plebiscito del 5 de octubre de 1988, tras el primer momento de festejo de los vencedores, en el estilo de las antiguas elecciones presidenciales, desató, en el correr de las semanas y meses siguientes, una visible descompresión en el país, un "estallido de la paz". ${ }^{46}$ Se resaltó un estado de ánimo colectivo de hastío con las divisiones y tensiones en la sociedad chilena. Todos volvían a ser amigos de todos. Las negociaciones que siguieron entre las partes y el plebiscito que siguió, aprobado por el 85,7 por ciento, produjeron reformas constitucionales de peso a la Carta, que reforzaban el pluralismo y limitaban el poder de veto de las fuerzas armadas, incomprensibles sin la presión de una nueva mentalidad que quizás ansiaba superar el pasado mediante el olvido. La oposición asumía, poco a poco, en la práctica, la economía política del régimen militar cuyo desarrollo en la década que siguió sería una marca de prestigio para el país. ${ }^{47} \mathrm{El}$ régimen aceptó entregar el poder — según su propia institucionalidad diseñada en su origen para el mismo Pinochet - y la oposición democrática se avino a una especie de firma de tratado de paz. En un reforzamiento irónico de este proceso, en gesto que para algunos apareció como sarcasmo pero que fue efectivo, Pinochet sacó de bajo de la manga otra carta, una según la cual la nueva democracia la había construido él junto al gobierno de las fuerzas armadas. No otra cosa fue su consigna de "misión cumplida". Hasta se podría decir que alguna razón le asistía. En todo caso, ni el régimen pudo imponer su proyecto original, ni la oposición democrática u oposición a secas obtuvo una capitulación del régimen como en Argentina, en 1983.

Así como en la crisis de la democracia hubo un factor internacional: la política mundial hacía que estuviéramos insertos de lleno en la

45 Gonzalo Vial, Pinochet: la biografia (Santiago: Aguilar/El Mercurio, 2002); Víctor Figueroa Clark, "The Forgotten History of the Chilean Transition: Armed Resistance Against Pinochet and US Policy towards Chile in the 1980s", Journal of Latin American Studies 47 (2015). Sobre el Tribunal Constitucional, véase Teodoro Rivera Neumann, "El Tribunal Constitucional y su aporte al derecho. Aspectos relevantes de los primeros 59 fallos”, Estudios Públicos 34 (1989).

${ }^{46}$ Alan Angell, Elecciones presidenciales, Democracia y partidos políticos en el Chile post Pinochet (Santiago: Centro de Estudios Bicentenario / Instituto de Historia de la Pontificia Universidad Católica, 2005).

${ }^{47}$ Patricio Navia, "Participación electoral en Chile, 1988-2001", Revista de Ciencia Política XXIV, n. ${ }^{\circ} 1$ (2004): 92. 
crisis ideológica del siglo. El momento de transición desde el autoritarismo a la nueva democracia - con un éxito extraordinario medido en la historia contemporánea del planeta - resultó posible debido a todo ese fenómeno que denominamos Caída del Muro, que fue mucho más allá de todo lo asombroso sucedido ese año 1989 y que reforzó, de un palazo, todo lo obrado en Chile (asumiéndose el modelo occidental e incluyendo a la sociedad civil económica). La transición fue una transacción, y también resumió —o repitió la historia - del tránsito del antiguo régimen a una democracia moderna como sucedió y sucede en muchos países de aquello que un tiempo se llamó Tercer Mundo. ${ }^{48}$

Entonces, ¿fue el factor internacional el decisivo como lo habría sido en el golpe de 1973? Me he rebelado contra esta interpretación establecida casi como dogma. El desarrollo posterior demostró que la democracia chilena tenía más garra que otras de la región y de más allá. Por ello, habría que considerar que la antigua tendencia chilena hacia la obediencia (o inercia, a veces) institucional predominó al momento de pensar y practicar, en torno a metas, procedimientos e instituciones de la política moderna. La transición a la democracia se desarrolló en lo que se ha llamado la "tercera ola de democratización" ${ }^{49}$ Chile había sido escogido como modelo (anti)moral, como antiutopía por el mundo de las democracias y no sólo por ellas. En los años de la Dina, mucha prensa europea y hasta norteamericana ponía a Chile en los titulares, aunque no hacía lo mismo con el genocidio en Camboya que se ejecutaba al mismo tiempo.

\section{ESPLENDOR Y MALESTAR: LA NUEVA DEMOCRACIA}

En muchos sentidos, ésta ha sido la mejor época de Chile. Desde fines de los 1980 abandonó su estatus de antiutopía y pasó a ser un modelo de adaptación al mundo contemporáneo, en especial aquél de la

48 Óscar Godoy, "Algunas claves de la transición política en Chile", Estudios Públicos 38 (1990); y "La transición chilena a la democracia: pactada", Estudios Públicos 74 (1999).

49 Samuel Huntington, La tercera ola, 19-40; Paul Sigmund, The United Stated and the Chilean Democracy (Baltimore: Johns Hopkins University Press, 1993); Mark Falcoff, Modern Chile 1970-1989. A Critical History (New Brunswick / London: Transaction Publisher, 1989). 
post Guerra Fría y de sus valoraciones ideales. Con casi unanimidad, el mundo euroamericano lo alabó como desempeño económico en comparación con otros de calidad análoga; ha sido muy citado y todavía lo es como un caso de éxito en lo político (democracia) y en lo económico. Nadie duda tampoco de que Chile todavía no es un país desarrollado, lo cual, a su vez, empalma con la evaluación de la democracia y con el debate de hoy y de siempre dentro de los límites de la modernidad.

Aunque en el siglo XXI disminuyeron un tanto las referencias positivas a Chile, haciendo un balance la imagen externa sigue siendo buena y ocasionalmente siguen apareciendo referencias positivas en este sentido. Las críticas han surgido fundamentalmente desde una perspectiva hostil al desarrollo del modelo occidental en el mundo, hacia aquello que se denomina demasiado esquemáticamente como "neoliberalismo", críticas que tuvieron mucho que ver con la evolución cultural e intelectual de América Latina. Sin embargo, como lo he afirmado en varias partes, uno puede estar convencido de que cuando esta época ya no se la viva, sobre todo de ser seguida por "tiempos revueltos", se la va a llorar, por mucho que carezca de epopeya. Los tiempos normales son poco propicios para una lectura heroica.

Ni en 1818, 1830, 1891 ni 1932 hubo una realidad o un sentimiento tan auspicioso como el que ocurrió en torno a 1990, cuando se configuran en su amplitud las bases de la nueva democracia en Chile. Existió un proceso de pacificación de los espíritus que fue tan importante como la evolución de la clase política y la relación de amistad cívica que se dio al interior de ella. Fue demasiado como para que no existiera después una pregunta de qué se olvidaba, a pesar de que tanto el recuerdo como el olvido son dos funciones esenciales de la existencia humana (y no puede haber una sin la otra). Esa pregunta tuvo, luego, su traducción en el orden político. Los dos plebiscitos y las elecciones parlamentarias y presidenciales que van de 1988 a 1989, con gran participación, parecieron fundar una realidad completamente nueva, $y$, en cierta manera, lo fue. Ni la investigación acerca de la razón de los muertos durante el régimen militar provocó un quiebre en el país; no obstante, el terrorismo residual cobró una víctima importante en Jaime Guzmán, principal asesor político del régimen militar y un actor especial en la última fase de la transición, con una extraordinaria capacidad de adaptarse a la 
nueva etapa que venía y en la cual aparecía como figura destacada y legitimada. ${ }^{50}$

En la primera mitad de los 1990, tanto el general Pinochet como la acción del régimen militar tuvieron reconocimientos incluso desde sus adversarios, y en parte, también, del mundo exterior. Fue una pequeña parcela de la época de la democracia de los acuerdos, que en algunos sentidos funcionó hasta bien avanzada la primera década del siglo XXI. Como régimen presidencial, la figura de los presidentes concitaba legitimidad especial con los límites de todo presidencialismo, del que se ha debatido pero el que todavía el país parece apoyar. Hubo dos figuras que reunían en sí las virtudes del antiguo y el nuevo Chile, o que por lo menos parecían como tales: Patricio Aylwin y Ricardo Lagos. Este último estaba dotado, además, del lenguaje intelectual, lo cual es probable que le dé peso en la memoria histórica. Pero en los dos primeros, Aylwin y Eduardo Frei Ruiz-Tagle — sexto hijo de Presidente que es Presidente-, permaneció casi inalterable la sensación de optimismo histórico. Además, en 1998 se cumplió un ciclo de quince años de crecimiento económico, el más largo desde que hay cifras, con especial brillo en la década de $1990 .{ }^{51}$

Los presidentes que siguieron reflejaron una realidad con más vericuetos, aunque no hay un quiebre en el impulso general ni finalmente en la percepción del país. Michelle Bachelet fue la primera mujer Presidenta y en la intimidad mantuvo una lealtad emocional hacia fórmulas radicalizadas junto con un desempeño racional y en lo básico de continuidad hasta el año 2010. Con Sebastián Piñera, la derecha retornó al poder con un dirigente que provenía del mundo socialcristiano, pero que adoptó con pasión las normas de la economía política que emergieron en el mundo desde la década de 1980. Fue la segunda vez, en más

${ }^{50}$ Para un libro completo sobre la década de los 1990, véase Carlos Huneeus, La democracia semisoberana: Chile después de Pinochet (Santiago: Penguin Random House, 2014). En la misma vena de mostrar una cierta falsedad de la democracia, Alfredo Jocelyn-Holt, El Chile perplejo. De avanzar sin transar, al transar sin parar (Santiago: Planeta, 1998). Lo mismo, Gabriel Salazar, La enervante levedad histórica de la clase política civil (Santiago: Debate, 2015).

${ }^{51}$ Patricio Navia, Las grandes alamedas. El Chile post-Pinochet (Santiago: La Tercera / Mondadori, 2003); Eugenio Tironi, “¿Es Chile un país moderno?”, en Cuánto y cómo cambiamos los chilenos. Balance de una década 1992-2002, de varios autores (Santiago: Instituto Nacional de Estadísticas, 2003), 15-76. 
de 60 años, que un candidato de derecha triunfaba por medios electorales, y su gobierno, en términos de calidad democrática tradicional, no desmereció del otro caso, Jorge Alessandri Rodríguez. También experimentó la mayor puesta en tela de juicio de la nueva democracia y del Chile actual, sin haber podido sacar una clara respuesta política de esto. Ello también incidió en la crisis que desencadenó el retorno de Michelle Bachelet con un triunfo electoral extraordinario y un empantanamiento posterior.

El arco político - y ésta fue la novedad frente a la democracia clásica- se articuló en torno a dos grandes coaliciones, en lo cual algún aspecto del sistema constitucional ayudó, como, por ejemplo, el rasgo binominal en los distritos electorales. Creo que esto, sin embargo, no es definitivo, ya que ni las elecciones presidenciales ni las municipales se regían por esta ley y tenían resultados parecidos. La articulación que comenzó con el plebiscito de 1988 respondía a una estructuración más permanente que el solo Sí o No. La polaridad no fue polarización, aunque tenía el aspecto complejo cada vez más evidente de que la política parecía una especie de mercado de intercambio entre una élite, restándole dinamismo. Ésta es una eterna historia de la democracia.

No es que no existieran desgarros. Uno de ellos fue la derrota político-cultural del pinochetismo, que se produjo particularmente después de la detención del general en Londres, en octubre de 1998, y que afectaba sin duda a la derecha, aunque en general se libró de ella. ${ }^{52} \mathrm{La}$ búsqueda por una justicia retrospectiva, apoyada en una fuerte presión cultural y política de la opinión pública mundial, incluyendo no pocas injusticias, no afectó sin embargo la estabilidad del sistema y, curiosamente, según varias encuestas, la percepción de los chilenos todavía ve a las fuerzas armadas y de orden como las instituciones más confiables del país. Resistió también los sucesivos cuestionamientos al orden constitucional producto de la escasa legitimidad de origen de la Constitución que le legaba el plebiscito de 1980. Su hito más significativo fueron las

52 Augusto Varas, Defensa nacional, Chile 1990-1994 (Santiago: Flacso, 1994); Claudio Fuentes, El discurso militar en la transición chilena (Santiago: Flacso, 1996). Mónica Pérez, Augusto Pinochet: 503 días atrapado en Londres (Santiago: Los Andes, 2000); Ernesto Ekaizer, Yo Augusto (Madrid: Aguilar, 2003); José Rodríguez Elizondo, Historia de la relación cívica-militar en Chile: desde Eduardo Frei Montalva hasta Michelle Bachelet Jeria (Santiago: Fondo de Cultura Económica, 2018). 
reformas del año 2005, consideradas, en su momento, por la gran mayoría de la clase política, como la vigencia de una nueva carta. Había temas pendientes, pero siempre flotaba un aire de crítica a pesar de que había acompañado al país en un momento que se veía como esplendor. Sin embargo, un rasgo importante del afloramiento de una conciencia de crisis en la segunda década del presente siglo XXI fue la idea de una nueva constitución y el debate respecto a la forma de impulsar el cambio. Éste podría ser una modificación y proclama como nueva carta; o bien, en el estilo del populismo latinoamericano, crear las bases para una transformación sustancial del régimen en un sentido más aproximado a la experiencia revolucionaria. ${ }^{53}$

Como en casi todo el mundo donde hay democracia y como le es inherente a su mismo ser, el problema de una época de normalidad es el eclipse del sentido. Es lo que en todo el mundo ha sucedido y que con resonancia freudiana podría definirse como "malestar con la política", desafección, indiferencia, rabia, también objeto de humor fácil. Primero se hizo visible con la caída de la participación electoral, ya que la inscripción era voluntaria y la votación, obligatoria; cuando en un gesto desesperado apareció una ley que hizo el procedimiento al revés - inscripción automática y voto voluntario-, creció la abstención, aunque con la participación de nuevos electores. Se ha dicho que esa abstención se explica por la falta de una real alternativa. Esto empujó, sobre todo, a los sectores que acompañaron a la coalición gobernante la mayor parte del tiempo, es decir, la centroizquierda, a tomar una posición de reformismo radical. Aquí operaba - junto con haber asumido el modelo occidental y recoger los frutos de un período mirado por muchos como

${ }^{53}$ Fernando Atria, La constitución tramposa (Santiago: LOM, 2013); Alberto Mayol, El derrumbe del modelo: la crisis de la economía de mercado en el Chile contemporáneo (Santiago: LOM, 2014); Claudio Alvarado, La ilusión constitucional. Sentido y límites del proceso constituyente (Santiago: IES, 2016). La crítica más profunda al nuevo Chile, y al mismo tiempo diferenciada y con un buen grado de sofisticación, es la de Tomás Moulian, Chile actual. Anatomía de un mito (Santiago: LOM, 2002); Joaquín Fermandois, "Verdad y mito del Chile actual", Estudios Públicos 69 (1998); Lois Hecht Oppenheim, Politics in Chile. Socialism, Authoritarianism, and Market Democracy (Boulder, Colorado: Westview Press, 2007); Carlos Ruiz, De nuevo la sociedad (Santiago: LOM, 2015). Que la noción de malestar no proviene de uno solo de los polos, sino que de una crítica a los rasgos de la modernidad, puede verse en el libro de Daniel Mansuy, Nos fuimos quedando en silencio (Santiago: IES, 2016). 
francamente próspero y pacífico - una mala conciencia por el cambio de posiciones y una actitud ambivalente ante la oleada neopopulista en la región.

Si la imagen externa y en parte la interna han sido una de éxito con el énfasis exagerado que se quiera, en esta mirada ha habido también una evolución. De manera gradual, aunque con pulsiones explosivas intercaladas, se han ido manifestando una crítica y un malestar que tienen que ver con las insatisfacciones económicas y sociales, como una reacción de mentalidad colectiva educada por las élites culturales ante una sociedad que muestra muchos de los rasgos de la llamada era postideológica. Esta última es una definición tan imperfecta como aquélla de neoliberal. La reacción procede de dos capas.

La primera es una capa más concentrada en las elites intelectuales y culturales, que luego, progresivamente, permea a grupos políticos que se sienten extraños por estas transformaciones y donde todos se suman a una reacción global, autodenominada de "crítica", contra la evolución del mundo post Guerra Fría, en especial en sus rasgos sociales y económicos, y en la aparentemente imparable interconexión social y económica que es, junto a una fragmentación, su contracara. En parte, esta crítica procede de una aprensión que me atrevo a llamar postmarxista, aunque por cierto el marxismo político o cultural tiene una cuota de presencia pero no alcanza a expresar la totalidad de esta visión.

La segunda fuente de reacción ha sido la insatisfacción social y económica percibida por grandes masas que no desconocen, sino que incluso aplauden, muchos aspectos de la evolución material, pero a la vez se sienten excluidos de sus beneficios o al menos de una parte que les correspondería. Cuando esto alcanzó la política afectó mucho más gravemente a la centroizquierda que a la centroderecha. Esta última sólo se veía afectada por carecer de una respuesta creativa a este fenómeno, aunque también se manifestó en diversos grados de aturdimiento por los cambios culturales y valóricos que tuvo que absorber sin digerirlos.

Lo interesante del caso es que - a pesar de que por un instante se logró conformar una gran mayoría unida en torno a la idea de un cambio, no muy distinta de la que, por señalar un metro comparativo, reinaba en el país a mediados de la década de 1960 - la condena al pasado reciente, sobre todo cuando implica el período de la nueva democracia, no alcanza a traducirse, en la práctica, en un abandono de esa estrella 
polar que comenzó a manifestarse con el Acuerdo Nacional de 1985. Además, los chilenos se lamentan por carencias en lo social y económico, pero a la vez declaran hallarse satisfechos con la vida que llevan. ${ }^{54}$ Por ello, hay que preguntarse si es que el malestar, salvo muchos casos puntuales pero al mismo tiempo claves — como educación, salud, rol de las grandes empresas, conflicto mapuche con quiebre de Estado de Derecho en una región, inseguridad que también es una suerte de crisis del mismo-, antes que un rechazo visceral del mundo de nuestro tiempo actualizado en Chile no es más que una expresión propia del proceso democrático, y que sería una suerte de Mayo de 1968, con mucho de carnaval, en el sentido original del término. Mi idea es que la situación está entremedio de los dos, en lo cual el estado del país no es diferente al de una realidad latinoamericana, aun dentro de una situación claramente mejorada en muchos aspectos, si bien no en todos.

Se ha citado mucho la mala distribución de los ingresos como una fuente de malestar. El índice Gini, por citar un caso, si se reconstruye históricamente no ha variado demasiado, salvo artificialmente durante la Unidad Popular. Dentro de América Latina, su posición en índice per cápita tuvo un avance hacia los primeros lugares, aunque existen ciertas actitudes socioculturales que le dan un rasgo distinto. ${ }^{55}$ Chile tiene la mala suerte de estar junto a la más importante democracia social de la región, Argentina, pese a que sí es un caso de desarrollo político frustrado; cuando no se compara con este vecino se hace con la OCDE, pero esto ya es harina de otro costal. En este último quinquenio, hasta donde nos permiten ver las cifras, la progresión en la distribución desigual ha tenido una tendencia a la disminución. Si ésta se relaciona con el crecimiento, se puede notar que todos los países de rápido mejoramiento económico manifiestan la misma tendencia, y hay que recordar que lo importante es si mejora la calidad de vida de la base de la pirámide social. Existen muchos elementos que permiten entregar una respuesta afirmativa a esta pregunta.

${ }^{54}$ De manera consistente, las encuestas CEP de los últimos años han mostrado que casi los dos tercios de los chilenos dicen estar satisfechos con su vida personal.

55 Para un estudio de la desigualdad en el Chile reciente, ver Harald Beyer, "¿Qué veinte años no es nada...? Una mirada a la desigualdad de ingresos a partir de las encuestas Casen”, Estudios Públicos 121 (2011). Más reciente, Claudio Sapelli, Chile: ¿país desigual? Una mirada a la dinámica del Chile de ayer, hoy y mañana (Santiago: Ediciones Universidad Católica, 2016). 
El modelo chileno ha sido admirado y zaherido. Líderes políticos y económicos lo citan como ejemplo; es de rigor que a la Cepal, aun reconociendo logros, le fascine señalar sus carencias. Se puede afirmar que, por más de cuatro décadas, al comienzo a empellones por dos sucesivas caídas abismales del producto, la economía chilena mostró que podía adecuarse a la nueva realidad y que el país poseía un potencial escondido asimilándose a la economía mundial de mercado. Aunque hubo algún tránsito de recursos naturales no renovables a renovables, al igual que el resto de América Latina y de la gran mayoría de las sociedades del mundo, Chile todavía no puede ser calificado como parte del mundo desarrollado. No se potencializó la innovación tecnológica ni el carácter abstracto del proceso económico más moderno. Sólo sucede que, dentro de la senda al desarrollo, este país dio un brinco en que mejoró de manera importante sus posibilidades y su calidad; a los límites antes señalados hay que anotar la idea de una persistencia adaptable, conductas no muy frecuentes en la región y en la historia de Chile. ${ }^{56}$ Quizás hay que mirarlo de otra manera. Lo que llamamos comúnmente desarrollo está, básicamente, situado en dos regiones del mundo: Europa occidental y las reproducciones suyas a lo largo del globo, y parte del mundo confuciano. Se puede decir que Chile, como sociedad y economía, se halla situado en un escalafón inmediatamente inferior.

Evaluar una democracia por sus carencias es parte de una labor crítica en el sentido apreciativo y parte, también, de una respuesta a que lo moderno, para poseer legitimidad, requiere de un mejoramiento del cual tenemos una noción inexacta pero no necesariamente falsa. En las últimas tres décadas ha habido una tendencia hacia una mayor estabilidad democrática en Argentina y Brasil, y algo fracturada en México. Chile aquí se compara con Uruguay en cuanto a que el malestar puede ser hasta el momento canalizado, aunque en nuestro país exista un cierto pasmo sobre la dirección a trazarse. $\mathrm{Y}$ en un marco global, se

56 José Luis Díaz Gallardo et al., La república en cifras: Chile 1810-2010. Historical statistics (Santiago: Ediciones Universidad Católica, 20016); Felipe Larraín y Rodrigo Vergara, ed., La transformación económica de Chile (Santiago: Centro de Estudios Públicos, 2000); Ricardo Ffrench-Davis, Entre el neoliberalismo y el crecimiento con equidad (Santiago: Cepal / LOM Ediciones, 2003). Un resumen en Rolf Lüders, "El proceso económico", en América Latina en la historia contemporánea. Chile. La búsqueda de la democracia, coordinado por Joaquín Fermandois (Madrid: MAPFRE, Taurus, 2015), tomo V. 
observa a España, que en cierta manera llegó a ser desarrollada, lo cual alienta esperanzas para el mundo latinoamericano; a pesar de la crisis financiera actual en relación con su historia, muestra también un afincamiento siempre precario, como le es propia a la democracia moderna. Desde un punto de vista macroeconómico y de legitimidad general del sistema, Chile no ha vivido la experiencia griega, teniendo en cuenta el paralelismo anotado en otras partes de este texto. Un espejo lejano pero que me parece imprescindible presentarlo es el caso de la India, con otro tamaño y otra complejidad. Con gran violencia dispersa, junto a una estabilidad democrática, recién una parte de la sociedad transita al desarrollo, aunque su camino será mucho más arduo. Es en este marco, y no en uno ideal que nunca se alcanzará, donde debe ser evaluada la posición de Chile para quien quiera entender y poder atreverse a expresar un juicio acerca de su calidad. ${ }^{57}$

Al destacar las posibilidades del modelo occidental en Chile, no se pueden perder de vista dos elementos sustanciales que se deben cultivar, si bien no deben someterse a una planificación, sino que son parte de una experiencia que se vive y visualiza. Uno es el vigor de una clase política entendida en un sentido amplio, que siempre termina constituyendo el factor clave de la democracia, con flexibilidad y duración, capacidad de transformarse y de transformar a sus críticos, de absorber y transmutarse en un sentido limitado, quizás sólo incremental. Además, para que la democracia signifique algo, al menos como punto de referencia de una continuidad republicana, debe estar acompañado al menos de otro fenómeno todavía más inasible y quizás más concreto y esencial para el proceso civilizatorio: las minorías creadoras, fecundo concepto de Arnold Toynbee que se manifiesta en el plano político, cultural, estético, social y económico. Jamás va a ser de una manera proporcional en todos ellos, pero debe cruzar más de una de estas esferas. La democracia no va a tener la solidez permanente ya que la precariedad le es inherente a su autoconciencia. Por ello, para que adquiera sentido y un fondo de referencia debe estar inserta en la experiencia de la cultura y civilización.

${ }^{57}$ Una reciente mirada sobre el tema, ver en Christopher H. Achen y Larry M. Bartels, Democracy for Realist. Why Elections Do Not Produce Responsive Government (Princeton / Oxford: Princeton University Press, 2016). 


\section{BIBLIOGRAFÍA}

Achen, Christopher H. \& Larry M. Bartels. Democracy for Realist. Why Elections Do Not Produce Responsive Government. Princeton / Oxford: Princeton University Press, 2016.

Ahumada, Jorge. En vez de la miseria. Santiago: Editorial Pacífico, 1958.

Allende, Salvador. "Discurso en la Asamblea General de Naciones Unidas, 4 de diciembre de 1972". En Salvador Allende y América Latina: 12 discursos y 2 conferencias de prensa, de Salvador Allende. México: Casa de Chile en México, 1978.

Alvarado, Claudio. La ilusión constitucional. Sentido y límites del proceso constituyente. Santiago: IES, 2016.

Álvarez, Rolando. Desde las sombras. Una historia de la clandestinidad comunista. Santiago: LOM, 2003.

Angell, Alan. Elecciones presidenciales, Democracia y partidos politicos en el Chile post Pinochet. Santiago: Centro de Estudios Bicentenario / Instituto de Historia de la Pontificia Universidad Católica, 2005.

Annio, Antonio, coordinador. Historia de las elecciones en Iberoamérica. Buenos Aires: Fondo de Cultura Económica, 1995.

Atria, Fernando. La constitución tramposa. Santiago: LOM, 2013.

Barros, Robert. La junta militar: Pinochet y la Constitución de 1980. Santiago: Editorial Sudamericana, 2005.

Bawden, John R. The Pinochet Generation. The Chilean Military in the Twentieth Century. Tuscaloosa: University of Alabama Press, 2016.

Beyer, Harald. "¿Qué veinte años no es nada...? Una mirada a la desigualdad de ingresos a partir de las encuestas Casen”. Estudios Públicos 121 (2011).

Candina, Azún. Clase media, Estado y sacrificio: La Agrupación Nacional de Empleados Fiscales en Chile contemporáneo (1943-1983). Santiago: LOM, 2013.

Casals Araya, Marcelo. La creación de la amenaza roja. Del surgimiento del anticomunismo a la "campaña del terror" en 1964. Santiago: LOM, 2016.

Corporación Nacional de Reparación y Reconciliación. Informe sobre calificación de víctimas de violaciones de derechos humanos y de la violencia política. Santiago: Corporación Nacional de Reparación y Reconciliación, 1996.

Corvalán Márquez, Luis. Del anticapitalismo al neoliberalismo en Chile. Izquierda, centro y derecha en la lucha entre los proyectos globales, 1950-2000. Santiago: Editorial Sudamericana, 2001.

- Los partidos políticos y el golpe del 11 de septiembre. Contribución al estudio del contexto histórico. Santiago: Universidad Bolivariana, 2000.

Dávila Avendaño, Mireya. Historia de las ideas de la renovación socialista 19741989. Tesis de licenciatura en historia de la Pontificia Universidad Católica de Chile, 1994. 
Devés, Eduardo. Los que van a morir te saludan. Historia de una masacre: Escuela Santa María de Iquique, 1907. Santiago: LOM, 1997.

Díaz Gallardo, José Luis, Rolf Lüders \& Gert Wagner. La república en cifras: Chile 1810-2010. Historical statistics. Santiago: Ediciones Universidad Católica, 2016.

Drake, Paul W. Between Tyranny and Anarchy. A History of Democracy in Latin America, 1800-2006. Stanford, California: Stanford University Press, 2009.

Edwards, Alberto. La fronda aristocrática: historia politica de Chile. Santiago: Universitaria, 1976.

Ekaizer, Ernesto. Yo Augusto (Madrid: Aguilar, 2003).

Elliot, J. H. Empires of the World. Britain and Spain in America 1492-1830. New Haven, Londres: Yale University Press, 2006.

Encina, Francisco Antonio. Historia de Chile: desde la prehistoria hasta 1891. Santiago: Editorial Nascimento, 1940-1952.

Falcoff, Mark. Modern Chile 1970-1989. A Critical History. New Brunswick / Londres: Transaction Publisher, 1989.

Fermandois, Joaquín. Abismo y cimiento: Gustavo Ross y las relaciones entre Chile y Estados Unidos. Santiago: Ediciones Universidad Católica, 1996.

_. "Modernización, desarrollo, dictadura: el papel de Sergio de Castro". Estudios Públicos 108 (2007): 281-313.

- Mundo y fin de mundo: Chile en la política mundial 1900-2005. Santiago: Ediciones de la Universidad Católica, 2005.

- La revolución inconclusa: la izquierda chilena y el gobierno de la Unidad Popular. Santiago: Centro de Estudios Públicos, 2013.

—. "Verdad y mito del Chile actual”. Estudios Públicos 69 (1998).

Fernández Abara, Joaquín. Regionalismo, liberalismo y rebelión: Copiapó en la guerra civil de 1859. Santiago: Editorial Finis Terrae, 2012.

Ffrench-Davis, Ricardo. Entre el neoliberalismo y el crecimiento con equidad. Santiago: Cepal / LOM Ediciones, 2003.

Figueroa Clark, Víctor. "The Forgotten History of the Chilean Transition: Armed Resistance against Pinochet and US Policy towards Chile in the 1980s". Journal of Latin American Studies 47 (2015).

Fontaine Aldunate, Arturo. Los economistas y el presidente Pinochet. Santiago: Zig-Zag, 1988.

Fontaine Talavera, Arturo. "Sobre el pecado original de la transformación capitalista chilena". En El desafio neoliberal: el fin del tercermundismo en América Latina, del compilador Barry Levine. 93-119. Barcelona: Norma, 1992.

Franco, Rolando. La Flacso clásica (1957-1973). Vicisitudes de las ciencias sociales latinoamericanas. Santiago: Flacso-Chile, Catalonia, 2007.

Fuentes, Claudio. El discurso militar en la transición chilena. Santiago: Flacso, 1996. 
Gárate Chateau, Manuel. La revolución capitalista de Chile: 1973-2003. Santiago: Ediciones Universidad Alberto Hurtado, 2013.

Garretón, Manuel Antonio. "Social Science and Society in Chile: Institutionalization, Breakdown and Rebirth". Social Science Information 44, n. ${ }^{\circ} 1$ y 3 (2005).

Gazmuri, Cristián, editor. El Chile del centenario, los ensayistas de la crisis. Santiago: Instituto de Historia de la Pontificia Universidad Católica, 2003.

Godoy, Óscar. "Algunas claves de la transición política en Chile". Estudios Públicos 38 (1990).

"La transición chilena a la democracia: pactada". Estudios Públicos 74 (1999).

- La democracia en Aristóteles: los orígenes del régimen republicano. Santiago: Ediciones Universidad Católica, 2012.

Góngora, Mario. Ensayo histórico sobre noción de Estado en Chile. Santiago: Universitaria, 2010.

Grez Toso, Sergio. "La izquierda chilena y las elecciones: una perspectiva histórica (1882-2013)". Cuadernos de Historia 40 (2014).

_. De la "regeneración del pueblo" a la huelga general. Génesis y evolución histórica del movimiento popular en Chile (1810-1890). Santiago: Dibam, 1997.

Hanisch, Walter. El catecismo politico cristiano. Las ideas y la época. Santiago: Andrés Bello, 1970.

Harmer Harmer, Tanya. El gobierno de Allende y la guerra fría interamericana. Santiago: Ediciones Diego Portales, 2013.

Hecht Oppenheim, Lois. Politics in Chile. Socialism, Authoritarianism, and Market Democracy. Boulder, Colorado: Westview Press, 2007.

Heise, Julio. Años de formación y aprendizaje políticos: 1810-1830. Santiago: Editorial Universitaria, 1978.

Huneeus, Carlos. La democracia semisoberana: Chile después de Pinochet. Santiago: Penguin Random House, 2014.

—. El régimen de Pinochet. Santiago: Debate, 2016.

Huntington, Samuel P. La tercera ola. La democratización a finales del siglo XX. Barcelona: Paidós, 1994.

Hurtado, Alberto. ¿Es Chile un país católico? Santiago: Ediciones Splendor, 1941.

Hurtado, Diego. Las palabras no se las lleva el viento: lenguajes políticos y democracia durante el gobierno de la Unidad Popular (1970-1973). Tesis de magíster en historia, Pontificia Universidad Católica de Chile, 2015.

Ibáñez Santa María, Adolfo. Historia de Chile: 1860-1973. Tomo II. Santiago: Editorial Bicentenario, 2014.

Jobet, Julio César. Ensayo histórico del desarrollo económico-social de Chile. Santiago: LOM, 1985. 
Jocelyn-Holt, Alfredo. El Chile perplejo. De avanzar sin transar, al transar sin parar. Santiago: Planeta, 1998.

Klein, Marcus. "La elección presidencial de 1938". En Camino a la Moneda. Las elecciones presidenciales en la historia de Chile 1920-2000, de los editores Alejandro San Francisco \& Ángel Soto. Santiago: Centro de Estudios Bicentenario / Instituto de Historia de la Pontificia Universidad Católica, 2005.

Krebs, Ricardo. Identidad chilena. Santiago: Centro de Estudios Bicentenario, 2008.

Larraín, Felipe \& Rodrigo Vergara, ed. La transformación económica de Chile. Santiago: Centro de Estudios Públicos, 2000.

Loveman, Brian. Chile: The Legacy of Hispanic Capitalism. Nueva York y Oxford: Oxford University Press, 2001.

Lüders, Rolf. "El proceso económico". En América Latina en la historia contemporánea. Chile. La búsqueda de la democracia, tomo V, coordinado por Joaquín Fermandois. Madrid: MAPFRE, Taurus, 2015.

Mansuy, Daniel. Nos fuimos quedando en silencio. Santiago: IES, 2016.

Mayol, Alberto. El derrumbe del modelo: la crisis de la economía de mercado en el Chile contemporáneo. Santiago: LOM, 2014.

Millar, René. La elección presidencial de 1920: tendencias y prácticas políticas en el Chile parlamentario. Santiago: Universitaria, 1982.

Moulian, Tomás. Chile actual. Anatomía de un mito. Santiago: LOM, 2002.

_. "El régimen de gobierno 1933-1973. Algunos problemas institucionales". Documento de Trabajo Flacso 406, mayo 1989.

Moulian, Tomás \& Isabel Torres Dujisin. "La reorganización de los partidos de la derecha entre 1983-1988”. Documentos de Trabajo Flacso 388, noviembre 1988.

Navia, Patricio. "Participación electoral en Chile, 1988-2001", Revista de Ciencia Política XXIV, n. ${ }^{\circ} 1$ (2004).

- Las grandes alamedas. El Chile post-Pinochet. Santiago: La Tercera / Mondadori, 2003.

Nunn, Frederick M. The military in Chilean History: Essays on Civil-military, 1810-1973. Albuquerque: Albuquerque University of New Mexico Press, 1976.

- The Time of the Generals. Latin American Militarism in World Perspective. Lincoln: University of Nebraska Press, 1992.

Ortega Frei, Eugenio. Historia de una alianza política: el Partido Socialista y el Partido Demócrata Cristiano. Tesis para optar al grado de licenciatura en historia, Pontificia Universidad Católica de Chile, 1992.

Pérez, Mónica. Augusto Pinochet: 503 dias atrapado en Londres (Santiago: Los Andes, 2000).

Perry, Mariana. La dimensión internacional del pensamiento político chileno. Aprendizaje y transferencia en el exilio. Tesis doctoral de la Universidad de Leiden, 2016. 
Pinto Santa Cruz, Aníbal. Chile. Un caso de desarrollo frustrado. Santiago: Universitaria, 1958.

Pinto Vallejos, Julio \& Verónica Valdivia. ¿Revolución proletaria o querida chusma? Socialismo y alessandrismo en la pugna por la politización pampina (19111932). Santiago: LOM, 2001.

Portales, Felipe. Los mitos de la democracia chilena. Santiago: Catalonia, 2004.

Purcell, Fernando \& Alfredo Riquelme, coordinadores. Ampliando miradas: Chile y su historia en el tiempo global. Santiago: RIL, 2009.

Puryear, Jeffrey. Thinking Politics. Intellectuals and Democracy in Chile, 19731988. Baltimore y Londres: The Johns Hopkins University Press, 1994.

Rivera Aravena, Carla. "La verdad está en los hechos: una tensión entre objetividad y oposición. Radio Cooperativa en dictadura". Historia 41, n. ${ }^{\circ} 1$ (2008).

Rivera Neumann, Teodoro. "El Tribunal Constitucional y su aporte al derecho. Aspectos relevantes de los primeros 59 fallos". Estudios Públicos 34 (1989).

Rodríguez Elizondo, José. Historia de la relación cívica-militar en Chile: desde Eduardo Frei Montalva hasta Michelle Bachelet Jeria (Santiago: Fondo de Cultura Económica, 2018).

Rojas Flores, Jorge. La dictadura de Ibáñez y los sindicatos (1927-1931). Santiago: Dibam, 1993.

Rojas, Gonzalo. Chile escoge la libertad. La presidencia de Augusto Pinochet Ugarte 11. IX. 1973 - 11. III. 1981. Santiago: Zig-Zag, 1998.

Rubio Apiolaza, Pablo. Los civiles de Pinochet. La derecha en el régimen militar chileno, 1983-1990. Santiago: Dibam, 2014.

Ruiz, Carlos. De nuevo la sociedad. Santiago: LOM, 2015.

Sagredo, Rafael. De la colonia a la república. Los catecismos políticos cristianos, 1811-1827. Madrid: MAPFRE, 2009.

Salazar, Gabriel, Construcción de Estado en Chile (1800-1837): democracia de los "pueblos", militarismo ciudadano, golpismo oligárquico. Santiago: Editorial Sudamericana, 2005.

L La enervante levedad histórica de la clase política civil. Santiago: Debate, 2015.

- Violencia politica popular en las "Grandes Alamedas". La violencia en Chile 1947-1987 (Una perspectiva histórico popular). Santiago: Sur, 1990.

San Francisco, Alejandro et al. Historia de Chile 1960-2010. Tomo I. Democracia, esperanzas y frustraciones. Chile a mediados del siglo XX. Santiago: Ediciones CEUSS, 2016.

- La guerra civil de 1891. Santiago: Centro de Estudios Bicentenario, 20072008.

Sapelli, Claudio. Chile: ¿país desigual? Una mirada a la dinámica del Chile de ayer, hoy y mañana. Santiago: Ediciones Universidad Católica, 2016.

Sartori, Giovanni. Teoría de la democracia. Madrid: Alianza Editorial, 1988. 
Sigmund, Paul. The United Stated and the Chilean Democracy. Baltimore: Johns Hopkins University Press, 1993.

Silva V., Fernando. "Un contrapunto de medio siglo". En Historia de Chile, de Sergio Villalobos, Osvaldo Silva, Fernando Silva \& Patricio Estellé. Santiago: Editorial Universitaria, 1977.

Silva, Patricio. "Technocrats and politics in Chile from the Chicago Boys to the Cieplan monks". Journal of Latin American Studies 23, n. ${ }^{\circ} 2$ (1991).

Tironi, Eugenio. “¿Es Chile un país moderno?”. En Cuánto y cómo cambiamos los chilenos. Balance de una década 1992-2002, de varios autores, 15-76. Santiago: Instituto Nacional de Estadísticas, 2003.

Tocqueville, Alexis de. De la Democratie en Amérique. París: Gallimard, 1961.

Urzúa Valenzuela, Germán. Historia política electoral de Chile: 1931-1973. Santiago: Editorial Jurídica, 1986.

Valdés, Juan Gabriel. La Escuela de Chicago. Operación Chile. Buenos Aires: Grupo Zeta, 1989.

Valenzuela, Arturo. El quiebre de la democracia en Chile. Santiago: Flacso, 1989.

Valenzuela, Samuel J. Democratización vía reforma. Expansión del sufragio en Chile. Buenos Aires: Ides, 1985.

Varas, Augusto. Defensa nacional, Chile 1990-1994. Santiago: Flacso, 1994.

Véliz, Claudio. Los dos mundos del Nuevo Mundo. Cultura y economía angloamericana e hispanoamericana. Santiago: Tajamar Editores, 2009.

Vergara, Rodrigo. "Sergio de Castro, el arquitecto del modelo chileno (comentario al libro de Arancibia y Balart)". Estudios Públicos 110 (2008).

Vial, Gonzalo. Historia de Chile (1891-1973). Volumen III. Arturo Alessandri y los golpes militares (1920-1925). Santiago: Santillana, 1987.

- Pinochet: la biografia. Santiago: Aguilar/ El Mercurio, 2002.

Villalobos, Sergio. Portales, una falsificación histórica. Santiago: Universitaria, 2016.

Ward, Robert E. \& Dankwart A. Rustow, editores. Political Modernization in Japan and Turkey. Princeton: Princeton University Press, 1964. EP 